\title{
CONSTRUCTION ELEMENTS OF THE TALLULAH FALLS DEVELOPMENT
}

\author{
BY CHARLES G. ADSIT
}

Assisted By W. P. HAMMOND

Abstract of PAper

The paper gives a very complete description of the Tallulah Falls hydroelectric development, which is of interest as being one of the highest head water power plants in the world. It was designed to supply electric power to the greater part of the State of Georgia. The paper includes complete unit costs of the various items of construction.

HE CONSTRUCTION of the Tallulah Falls hydroelectric development has some particular interest attached to it as being the highest head hydroelectric plant east of the Mississippi River, and one of the highest in the world using water power turbines. This development is situated on the eastern slope of the Blue Ridge mountains in Rabun and Habersham Counties in North Georgia and was placed in operation during September, 1913, having been under construction at that time for a period of $2 \frac{1}{2}$ years. The head under which the plant operates is $606 \mathrm{ft}$., which is obtained by the natural fall of the Tallulah river and the $110-\mathrm{ft}$. dam. The entire development is in the Tallulah River basin, this river being a tributary to the Savannah and rising in the Blue Ridge mountains of North Georgia. The drainage area above the Tallulah diversion dam is 190 square miles, all of which is very heavily timbered and from which an apparently abnormal annual run-off occurs. The rainfall on this water shed ranges from 65 to 80 inches per annum, which with the storage reservoir and the present installation allows the development to use an average of two ft. per second per square mile run-off throughout the year. The river is subject to frequent floods during the spring season from 5000 to 8000 second-feet, the maximum ever recorded being 15,000 second-feet in March 1912.

The purpose of the development is to supply the greater 
portion of the state of Georgia with power, with Atlanta and vicinity as the principal market.

A general description of the development involves a description of a number of construction details.

In order to carry out the development, it was deemed advisable to install a small power plant at one of the falls in the Tallulah river in order to furnish compressed air and electrical energy for lighting and power purposes during construction. This small plant included the installation of two water-driven air compressors of $2500 \mathrm{cu}$. ft. capacity for compressing the air to $110 \mathrm{lb}$. per sq. in., and two 50-kw., 2300-volt, three-phase, 60 -cycle generators, also water-driven. In addition to this equipment it was later found necessary to install an 1825-cu. ft. compressor driven by steam and located at the lower end of the works farthest from the water driven plant. The air was then used for all power purposes except lighting, at the main dam, tunnel, forebay, penstocks and power house. This small plant operated under a 40 -ft. head and was entirely removed after the construction work was completed.

To assist in the construction it was necessary to build three spur tracks from the main line of the railroad serving this section, the one in connection with the Mathis dam being $1 \frac{1}{2}$ miles in length, the one at the intake dam $\frac{1}{4}$ mile in length and the one to the forebay above the power house about one mile.

The development consists essentially of an artificial reservoir of a capacity of $1,400,000,000 \mathrm{cu}$. ft. formed by two reinforced concrete buttress dams located near Mathis, Ga., seven miles above the diverting dam and intake at Tallulah Falls; an artificial reservoir at Tallulah Falls having an available pondage of $63,000,000 \mathrm{cu}$. ft. formed by a cyclopean masonry dam of the gravity type located some $60 \mathrm{ft}$. below the tunnel intake; a tunnel with a cross sectional area of 151 sq. ft. 6666 ft. long leading from the intake at the Tallulah reservoir to the surge or pressure tank at the top of the gorge immediately above the power house; five steel penstocks $5 \mathrm{ft}$. in diameter, each of which serves a 17,000 -h.p. Francis type water turbine in the power house. Five three-phase, 60-cycle, 6600-volt vertical generators are direct-connected to these waterwheels.

The electrical energy from these machines is stepped up from 6600 volts to 110,000 volts for transmission by five banks of three $3333-\mathrm{kw}$. single-phase static transformers of the watercooled type. 


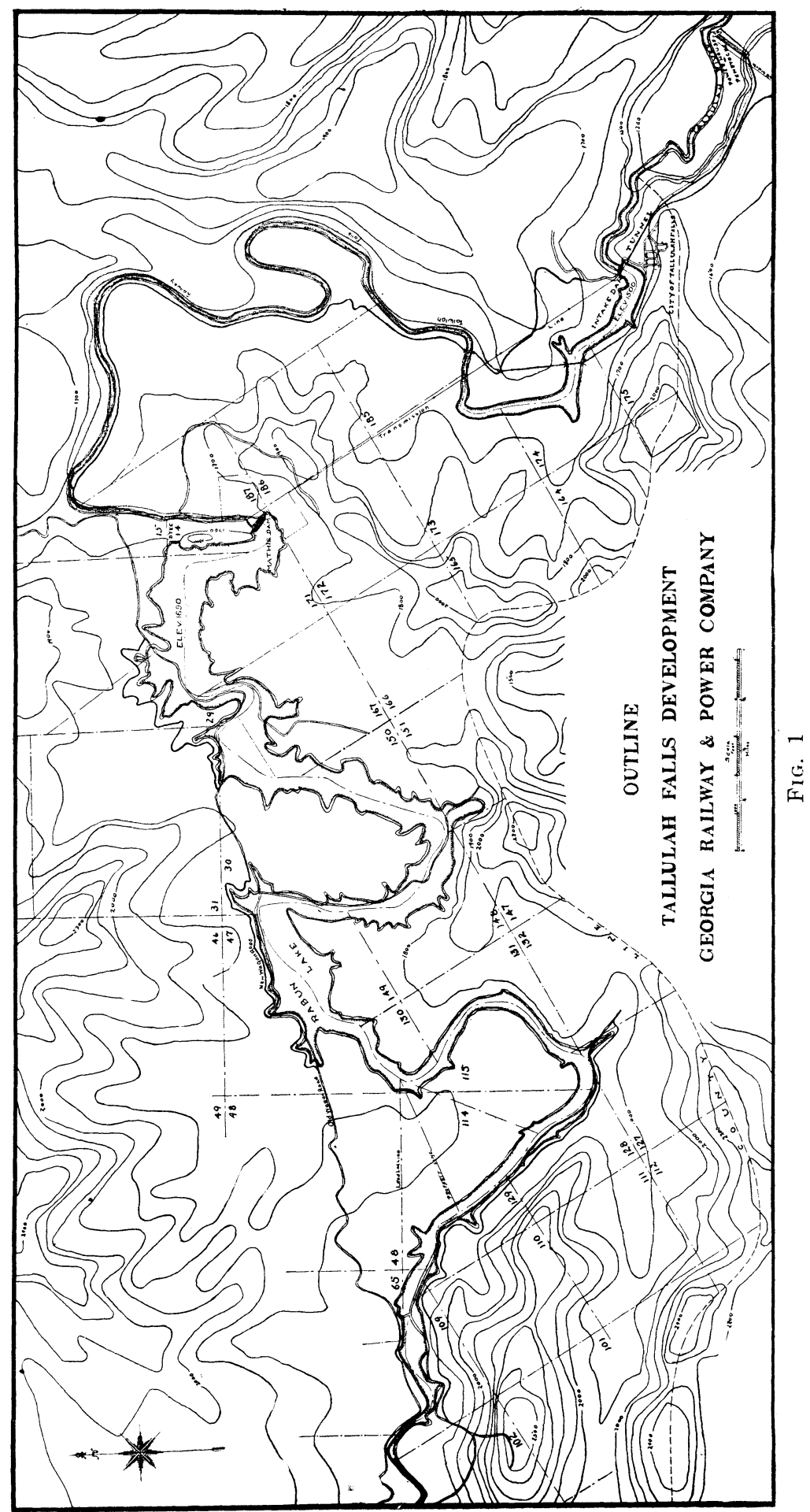


The power house consists of a main generating building and a transformer and switch building, both buildings being of concrete substructure and steel and brick superstructure.

The power is transmitted from this plant over two trunk lines, one leading to Atlanta, a distance of 87.2 miles, and the other to Greenville, S. C., 60 miles. The Atlanta line is carried on steel towers and consists of two three-phase circuits of $4 / 0$ copper conductors on suspension type insulators, with a $7 / 16$ in. steel strand ground wire, above each circuit, the four wires being arranged in a vertical plane with 9 -ft. centers between the power conductors. On the Atlanta end of this line is located a large outdoor type substation of $60,000-\mathrm{kw}$. capacity, from which both high- and low-tension distribution is made. There is also connected to this main trunk line at Gainesville, Ga., a station half-way between Tallulah and Atlanta, a 1500$\mathrm{kw}$. outdoor type substation for distributing low-tension power to the city of Gainesville and adjacent territory. From the Atlanta substation, a 110,000-volt line extends to Newnan, Ga., a small town 42.1 miles southwest of Atlanta, and to Lindale, Ga., 69.2 miles northwest, where connection is made with the high-tension system of the Tennessee Power Company.

Both of these lines are strung on steel towers provided for double circuits, but at present only one circuit has been installed on each line. The conductors are $2 / 0$ copper, and the ground wire $\frac{3}{8}$-in. steel strand, the arrangement being essentially the same as on the Tallulah-Atlanta line. The capacity of the Newnan station is $3000 \mathrm{kw}$., and of the Lindale $6000 \mathrm{kw}$. There has already been constructed along the Atlanta-Lindale line, two outdoor type substations, one at Marietta, Ga., 16.8 miles from Atlanta, of 3000-kw. capacity, and one at Cartersville, Ga., 23.3 miles beyond Marietta, of the same capacity, while provisions have been made in the way of steel switching frames at a number of other points along both of these lines for similar installations, and for doubling the capacity of those stations already in operation when the demand justifies doing so. A number of low-tension lines also emanate from the Boulevard station at Atlanta for supplying power to the various mills and other stations located in that vicinity.

In order to treat of the development from a construction standpoint, it will be necessary of course to take up the above elements individually and give a closer description under the separate headings. 


\section{Mathis Dams}

The construction of the Mathis dams was for the purpose of impounding sufficient water to carry the Tallulah Falls station through the dry months of the year, usually September, October and a part of November. These dams form a pond or lake some 10 miles long with 26 miles of shore line and of a capacity of $1,400,000,000 \mathrm{cu}$. ft. The reservoir covers 834 acres, most of which was heavily timbered prior to the construction period. Both dams are of reinforced concrete construction as shown in the accompanying illustrations, Figs. 2, 3, and 4, and consist of heavy reinforced buttresses with a deck on the upstream face at an angle of 45 degrees. The largest dam is in the Tallulah river six and one-half miles above the intake at Tallulah falls,

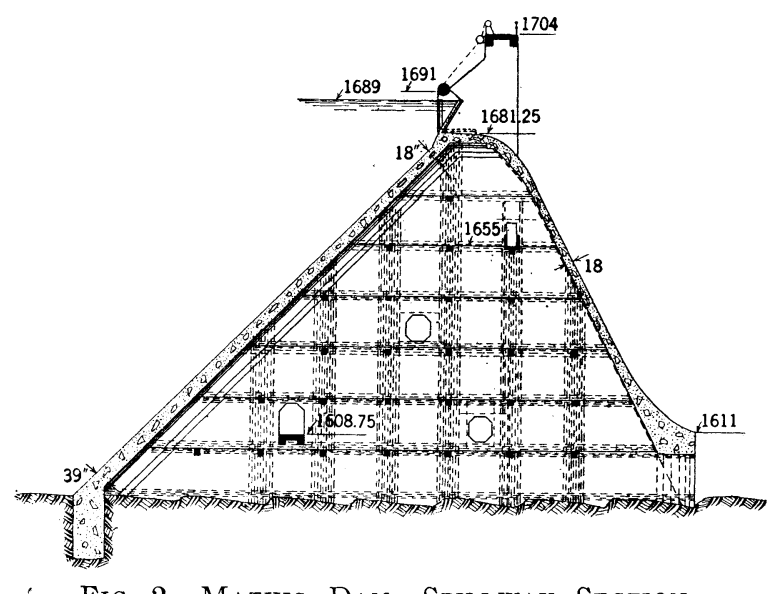

Fig. 2-Mathis Dam-Spillway Section

and is $660 \mathrm{ft}$. in length, $93 \mathrm{ft}$. high to the crest of the spillway concrete and $114 \mathrm{ft}$. to the top walkway. The other dam is a much smaller one and was made necessary by a depression in the hills about $1000 \mathrm{ft}$. above the larger dam. This dam is of similar construction, with the exception that it was necessary to lay a heavy reinforced concrete mattress over the entire dam foundation, in order to carry the stresses imposed on the foundation by the buttresses. The rock encountered at this dam was badly weathered, shattered and so full of micaceous material that it was not deemed advisable to depend solely on the area of the buttress footings for support. The cut-off wall was carried through this bad ground to a depth of $50 \mathrm{ft}$. below the base of the dam; this wall being also reinforced. The specifica- 
tions called for a 1-3-6 concrete mixture with aggregate passing a $2 \frac{1}{2}$-in. mesh screen for all floors, buttresses and abutments, and a 1-2-4 mixture with two-inch aggregate in all decks, crests and aprons. The reinforced steel was used of the "corrugated bar" type. The quantities involved in the construction of these two dams were $2,200,000 \mathrm{lb}$. of steel reinforcing, and 38,000 cu. yd. of concrete.

A power house (Fig. 5) was constructed in the main dam to take advantage of the flow of water through this dam and add the additional power thus produced to the output of the main generating station. This power house is of concrete substructure and brick and steel superstructure, and has space for the installation of two $3000-\mathrm{kw}$. horizontal water-driven generators.

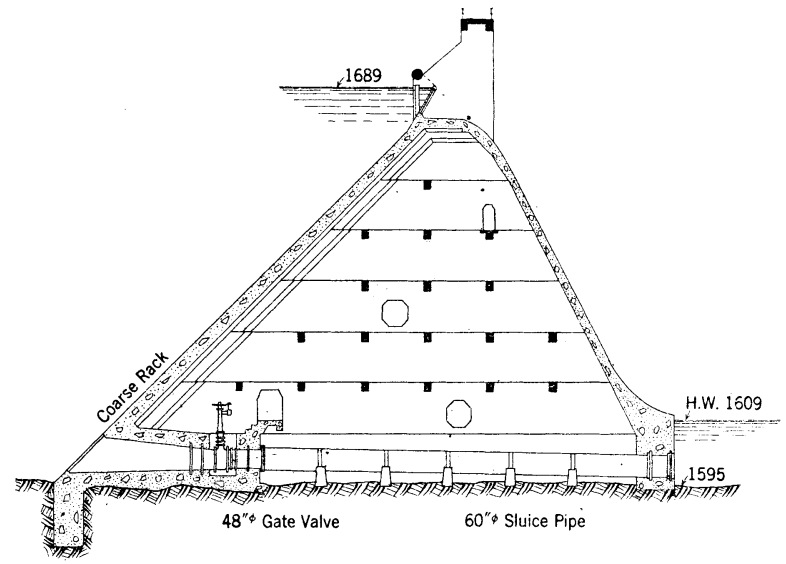

Fig. 3-Mathis Dam-Section through Sluiceway

The main dam has a spillway section $256 \mathrm{ft}$. in length and in order to impound more water is fitted at this section with flashboards six ft. high above the concrete crest of the dam. The flashboards are built in sections $16 \mathrm{ft}$. in length with concrete piers between, seven sections of which are automatic and so designed as to retain the pond level at a constant elevation regardless of flood conditions, within certain limits. There are in addition to these seven automatic flashboards, nine hand-operated ones, which are similar to the automatic boards except that they are raised or lowered only by manual operation.

The entire reservoir was cleared of timber, brush and other debris before impounding began, at a cost of $\$ 21$ per acre, represented by $\$ 8.35$ for cutting and $\$ 12.65$ for gathering and burning. 
PLATE CXLII.

A. I. E. E.

VJL. XXXIV. 1915

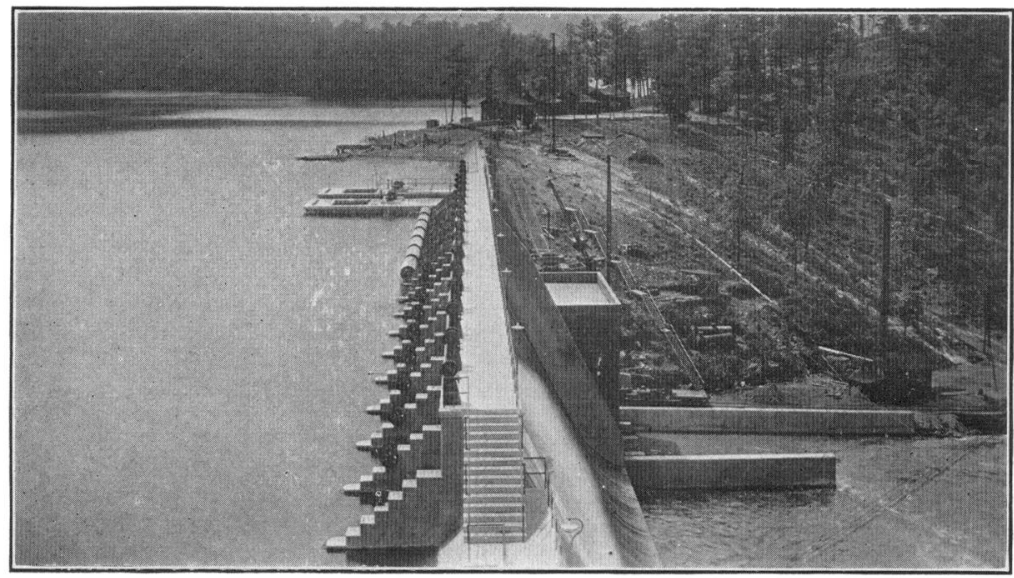

[ADSIT AND HAMMOND]

Fig. 4-Main Mathis Dam-Reservoir Full

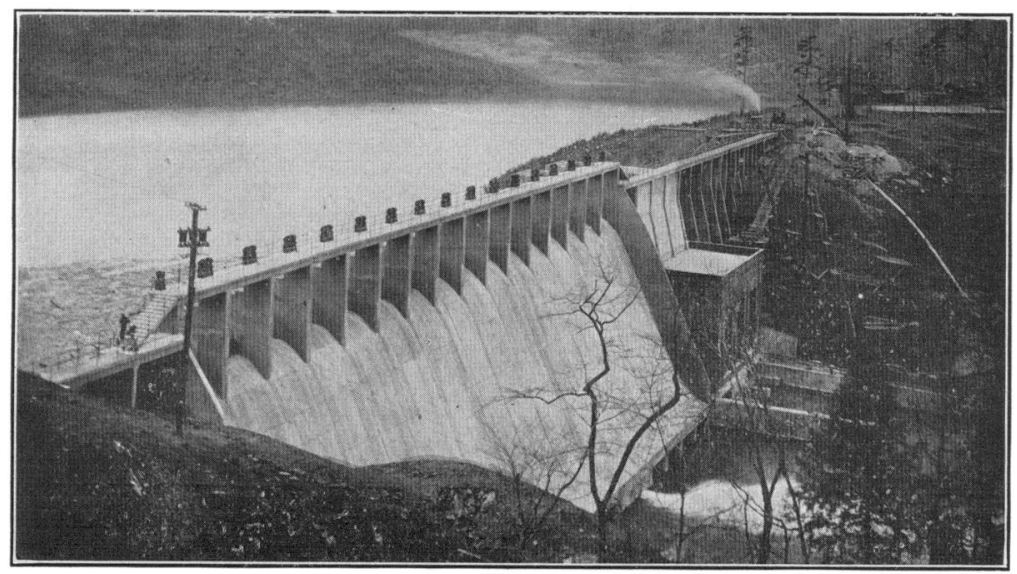

[ADSIT AND HAMMOND]

Fig. 5-Main Mathis Dam 
PLATE CXLIII.

A. I. E. E.

VOL. XXXIV, 1915

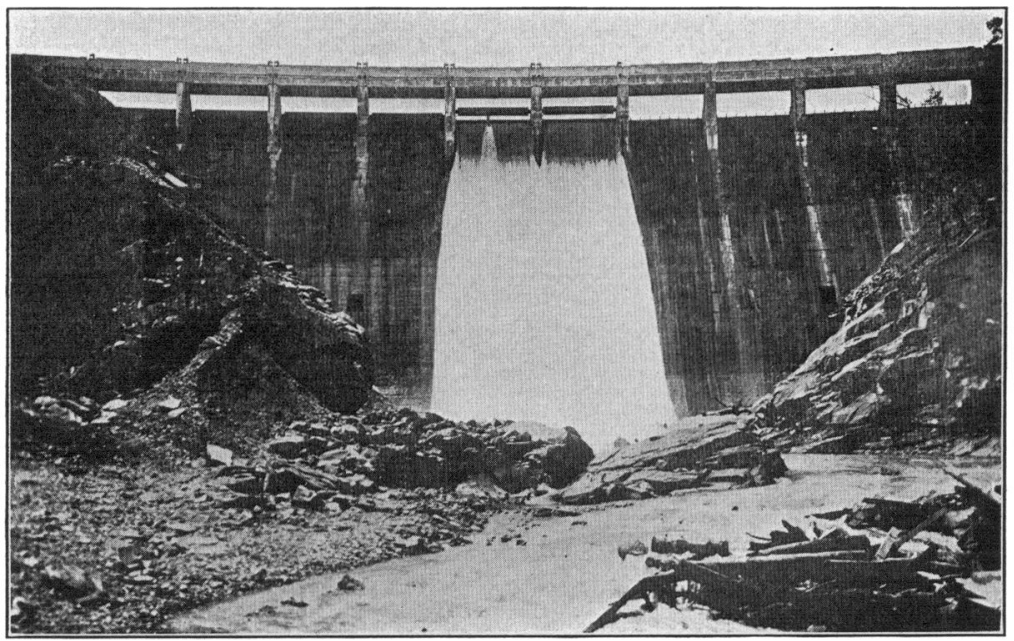

[ADSIT AND HAMMOND]

Fig. 7-Intake DaM

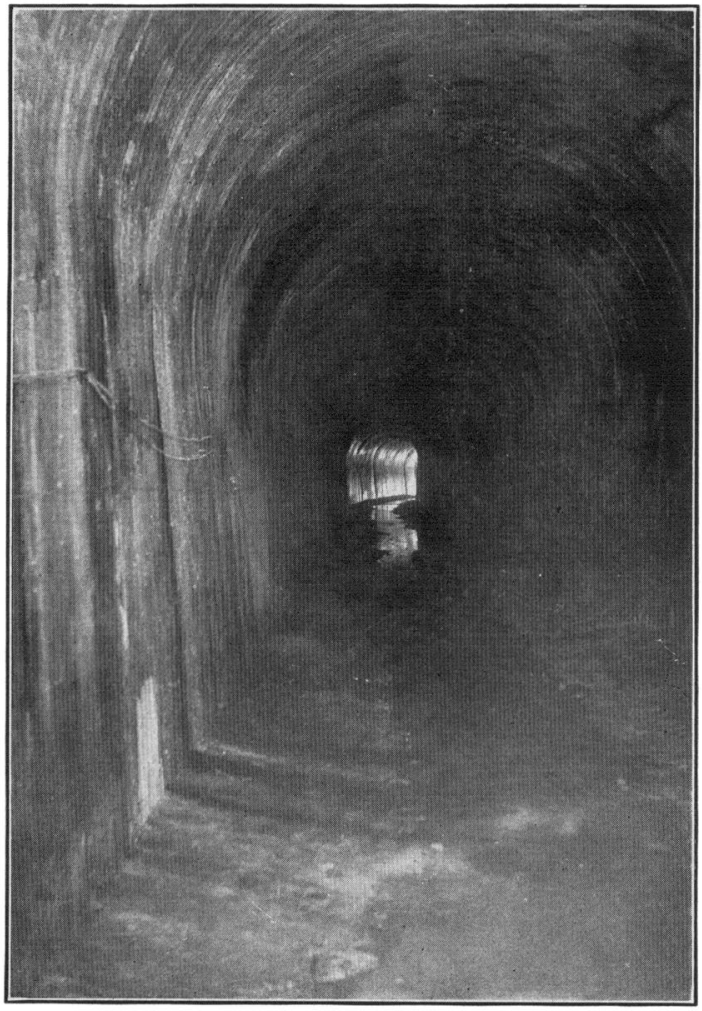

[ADSIT AND H.AMMOND]

FIG. 12 
The following figures give the tabulated cost per cubic yard of these two dams:

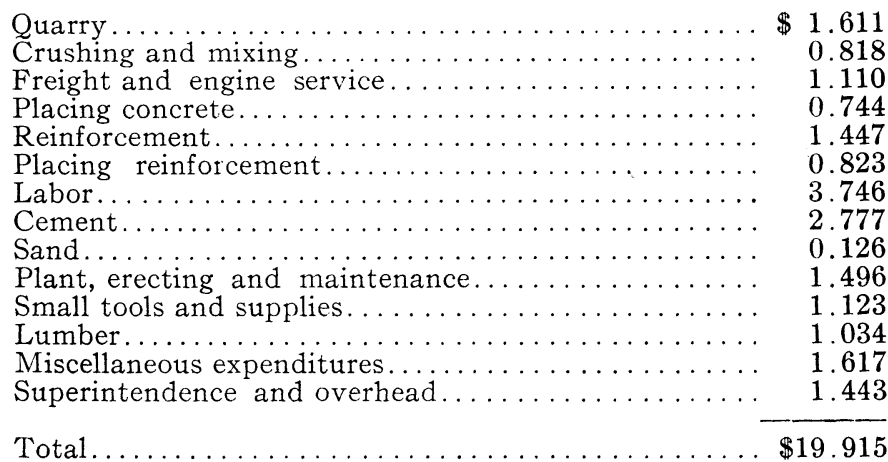

It should be stated, however, in connection with these figures, that the construction of these dams was attended with considerable legal trouble and interference. Also a change of design of many portions after the work was well along. The work was first undertaken under contract, but was given up by the contractors before it had been completed, and considerable time was then lost and unnecessary expense incurred which shows up in the yardage cost. The first contractors on this dam attempted to find satisfactory rock for concrete at the dam site, but the quality of material coming from this quarry was very unsatisfactory. The nearest point at which good material could be found was the quarry at Tallulah Falls, which had been used in connection with the construction of the intake dam, and the greater portion of the rock for the two Mathis dams was then secured at this place, which involved the handling by rail over a distance of some seven miles.

\section{The Diverting Dam}

The diverting dam, a section of which is shown in Fig. 6, is of the gravity type and built of cyclopean masonry, heavy stone forming a little over one-third of the mass, and concrete mixture the other two-thirds, of the composition $1-3-5$. This dam is 110 $\mathrm{ft}$. high from the stream datum and has a length of $426 \mathrm{ft}$. It is built on a curved plan with a radius of $900 \mathrm{ft}$., and has a spillway section of $280 \mathrm{ft}$. in length, made up of ten 28 -ft. openings between concrete piers which support a highway bridge across the top. Fig. 7 shows automatic flashboards $6 \mathrm{ft}$. high that are installed between six of these concrete piers for maintaining the crest of the pond at a given elevation within certain flood limits. The other four openings are fitted with stationary boards so designed as to give way entirely should a flood ever occur that 
the automatic boards cannot take care of. There are two five-ft. sluice ways in the dam, $65 \mathrm{ft}$. below the crest, which in addition to the spillway gives an overflow capacity of something less than 20,000 second-ft. The flashboards have been found to operate with a change of three inches in the water elevation of the pond. It was necessary in the construction of these flashboards, Fig. 8 , to build the concrete weights or rollers in place, each weighing $34,000 \mathrm{lb}$, which are attached to the flashboards with two steel cables. These weights travel on an inclined track,

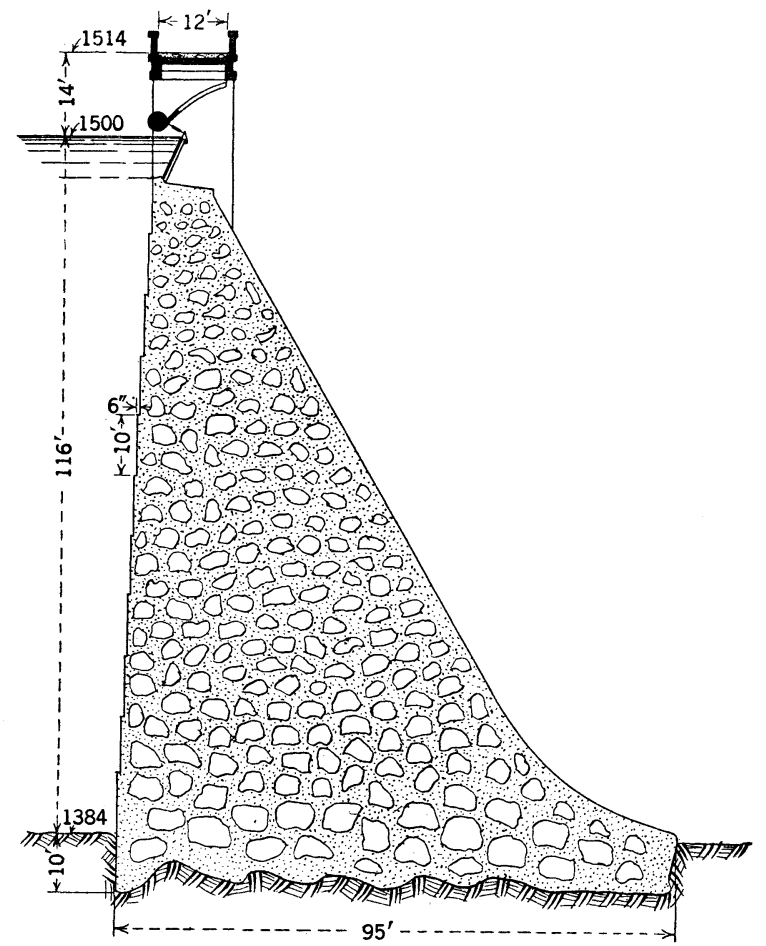

Fig. 6-Cross-Section of Intake Dam

each end being supported by a geared sprocket fitting into racks along the track which prevent the rollers or weights from turning without moving along the track.

There were used in the construction of this dam $39,000 \mathrm{cu}$. yd. of concrete which was placed by the contractors at a price of $\$ 4.80$ per cu. yd., the construction of the bridge piers and flashboards being additional to this amount. The cement used was furnished to the contractors for $\$ 1.80$ per barrel, less 10 cents for the return of each sack. The contract price for the excava- 
tion work in the dam foundation was $\$ 1.50$ per cu. yd. regardless of whether wet or dry. It is the opinion of the writer that the cyclopean masonry actually cost the contractors about $\$ 3.70$ per yd. In analyzing this cost, several facts should be borne in mind; the quarry for all stone was within $300 \mathrm{ft}$. of the structure, all sand used was rolled from this rock, and no material entering

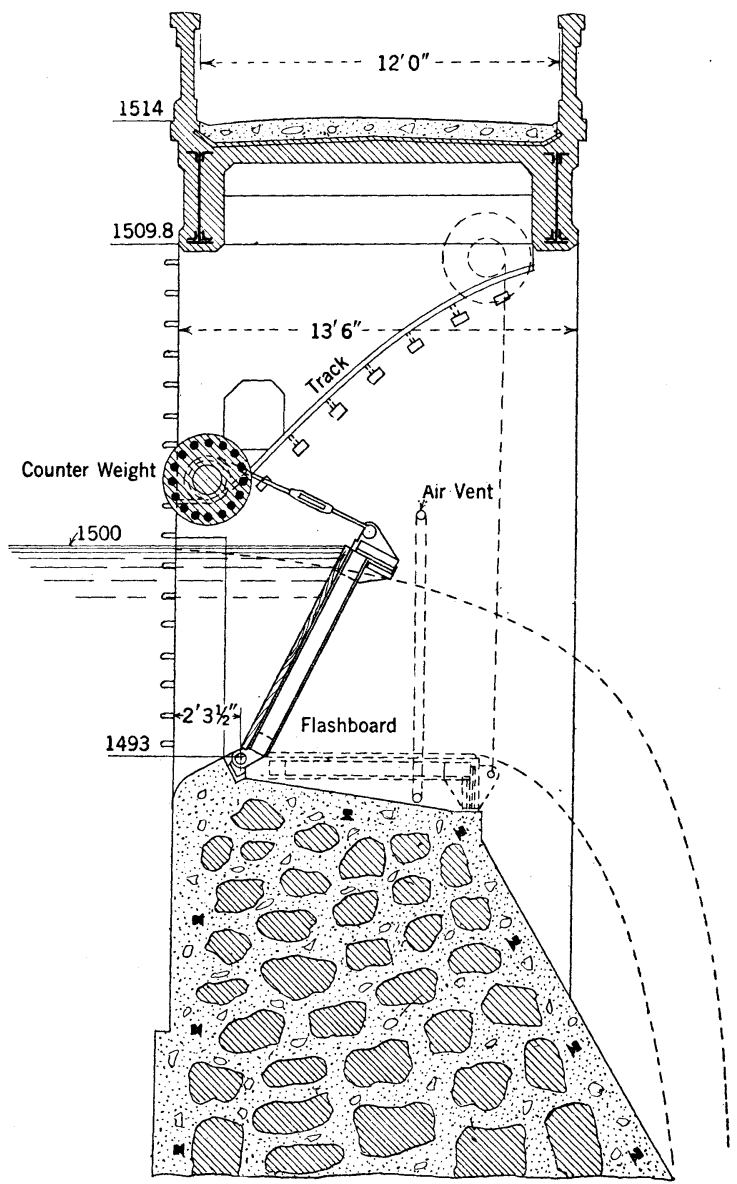

Fig. 8-Intake Dam-Crest Detail

the structure had to be transported except the cement and reinforcing.

The bridge on top of the dam is constructed of steel girders spanning the piers with reinforced concrete deck and railing, the steel girders being afterwards encased in concrete.

It might be interesting to note that while the contract speci- 
fications called for $33 \frac{1}{3}$ per cent large rock in the construction of this dam, the actual percentage in the finished structure was found to be 34 per cent.

The construction of the dam was commenced in August 1911 and the first concrete poured late in October, the construction then continued at the rate of $1000 \mathrm{cu}$. yd. per week until completed. Little difficulty was encountered during this period, with the exception of one flood during March 1912, which overflowed the work, notwithstanding the provision of two 12 -ft. square flood openings in the base of the dam. This flood washed away about $250 \mathrm{cu}$. yd. of concrete which had

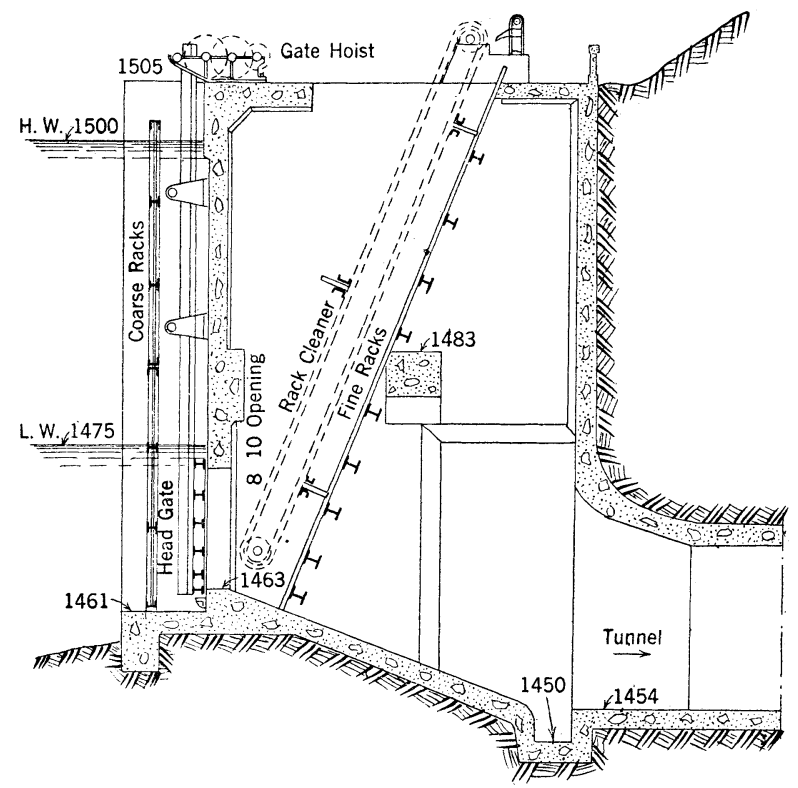

Fig. 9-Tunnel Intake

not sufficiently set to withstand the action of the water. No provision was made in the dam for expansion and contraction, the cracks resulting from this action being left to form of their own accord. During the construction period the temperature ranged from $110 \mathrm{deg}$. to $10 \mathrm{deg}$. fahr., and only two temperature cracks developed, neither of which leaked.

\section{The INTAKE}

The intake as shown in Figs. 9 and 10 is a self-contained, reinforced concrete structure designed to withstand the stresses due to hydrostatic pressure when the pond is at its maximum 
elevation and the intake empty, the rock at this point being badly weathered and thoroughly broken. In order to increase the strength of the structure it was designed in five bays with arched dividing walls, the construction involving about 7000 cu. yd. of excavation, mostly rock, and $2670 \mathrm{cu}$. yd. of concrete. The reinforcing consists of heavy steel beams and $\frac{7}{8}$-in. round rods spaced on three-inch centers.

There are included in the structure five $8 \mathrm{ft}$. by $10 \mathrm{ft}$. intake gates operated by hand hoists. Coarse racks are placed outside these gates to take care of heavy material, and additional finer racks made up of $\frac{3}{8}$-in. by 4 -in. flat bars spaced $1 \frac{1}{4}$ in.

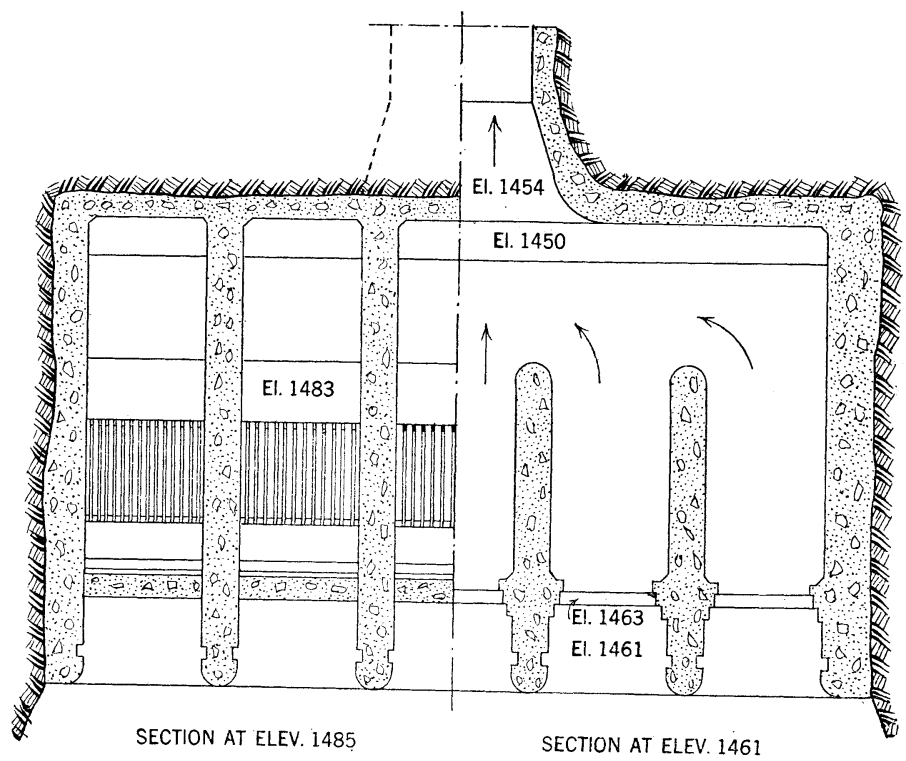

Fig. 10-Tunnel Intake

apart are placed on an angle inside the gates. An automatic rack cleaning device in three of the bays consists of rakes operated on an endless chain driven by an electric motor through worm gearing. These rakes are driven at a speed of three feet per minute, and each rake designed to lift $100 \mathrm{lb}$. per lineal foot. It is interesting to note at this point that none of these racks have ever been cleaned, no debris having ever been found within the gates. The apparent reason for this is, that the gates are about $25 \mathrm{ft}$. below the elevation of the water in the pond, so that no floating material ever reaches the action of the inrushing water. The head gates are built up of riveted steel 
plates and beams with bronze sliding strips. The detailed cost of excavation and concrete for the intake is as follows:

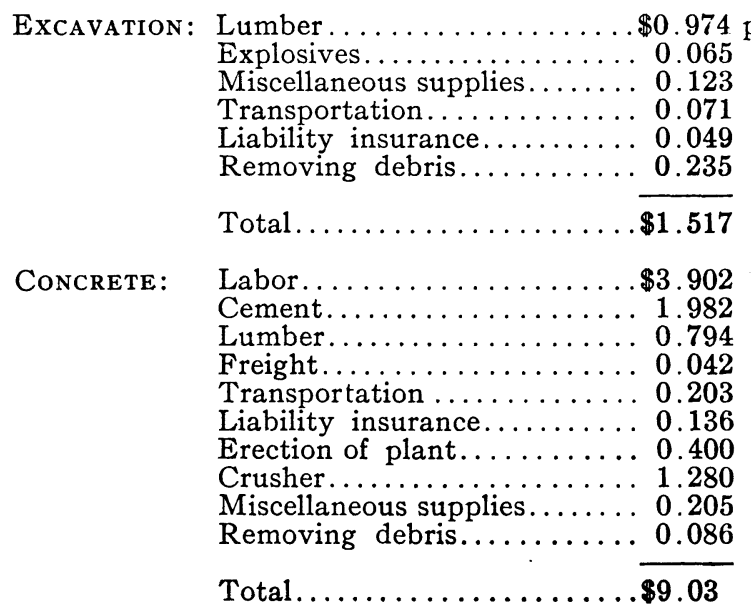

The Tunnel

Beginning at the intake, a concrete-lined tunnel, $6666 \mathrm{ft}$. long, having a net area of 151 sq. ft. inside the concrete lining, conveys the water to the surge or pressure tank located at the upper end of the penstocks. A circular section might have been more favorable for serving the purpose, but as no extremely high hydrostatic pressure was anticipated, a section as shown in Fig. 11 was adopted; this form being much easier to excavate and line with concrete than a circular section. This tunnel was driven on a grade of two ft. drop per 1000 , or 0.2 per cent. The tunnel was driven as near the gorge as it was possible to construct it with safety, and it was found desirable to facilitate the excavating and lining by driving three adits from the tunnel line to the side of the gorge, and sink one shaft from the surface of the ground down to the tunnel line, $110 \mathrm{ft}$. These adits were $7 \mathrm{ft}$. high and $15 \mathrm{ft}$. wide, the longest one 217 $\mathrm{ft}$. and the shortest one $105 \mathrm{ft}$. Throughout its length, a hard micaceous quartzite, was encountered in the tunnel excavation, the stratification dipping down stream at an angle of about 22 deg. from the horizontal. This rock was of highly crystalline nature and extremely abrasive, the drill bits usually losing about $\frac{1}{4}$ in. of their diameter per foot of hole. During the first part of the construction work $3 \frac{5}{8}$-in. piston drills driven by compressed air were used but the progress was so slow, especially in the dry holes, as to make a change of drilling equipment imperative; the use of 100 pieces of drill steel for one dry hole not being 
infrequent. Water core hammer drills were then substituted for the piston drills and twice the progress made, which proved the salvation of the tunnel construction. The use of approximately $15 \mathrm{lb}$. of drill steel per lineal foot of tunnel is also an indication of the extreme drilling conditions which were met with. About 75 per cent of the tunnel was driven by the top-heading

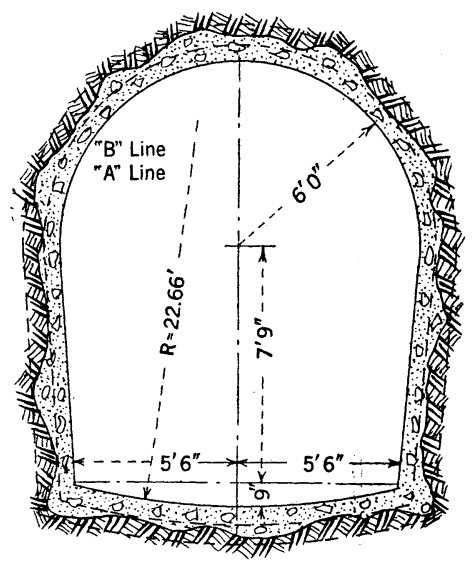

Fig. 11-Tunnel Section method, but the direction work was partially taken out of the contractor's hands, and the lower heading or stopping method instituted on the remainder of the work. A comparison of the cost of the two methods shows a difference of 52 cents per cubic yard in favor of the latter. The lower-heading method allowed a much greater progress, as it did not involve pulling of the ground in the tunnel arch, nor did it involve the double drilling which was necessary to remove the bench left by the upper heading method. A detailed comparison of the cost of the two methods is given in the following tables:

Items

Labor.

Superintendent and walking bosses......

General expenses..................

Office force...................

Storeroom force................

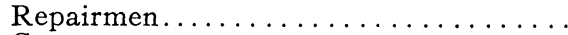

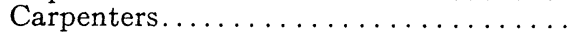

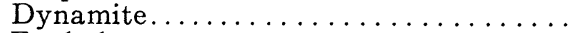

Exploders.......................

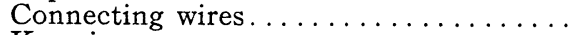

Kerosine.....................

Lubricating oil................

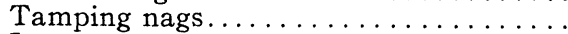

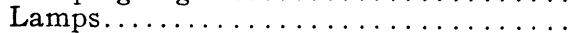

Piping and fittings............

Drill repairs.....................

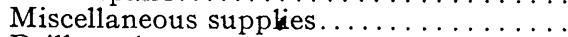

Drill steel. . . . . . . . . . . . . . . . .

Blacksmith coal.................

Freight...................

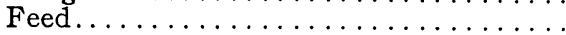

Total
Cost per cubic yard

\section{Stoping Bench} work

$\$ 2.415$

0.141

0.036

0.103

0.027

0.115

0.053

0.0329

0.029

0.015

0.002

0.013

0.002

0.011

0.015

0.204

0.041

0.107

0.027

0.063

0.031
$\$ 2.965$

0.067

0.101

0.085

0.028

0.102

0.050

0.416

0.038

0.014

0.002

0.012

0.002

0.010

0.029

0.095

0.063

0.080

0.027

0.079

0.050 
The unit cost of excavating $39,831 \mathrm{yd}$. of this tunnel was as follows:

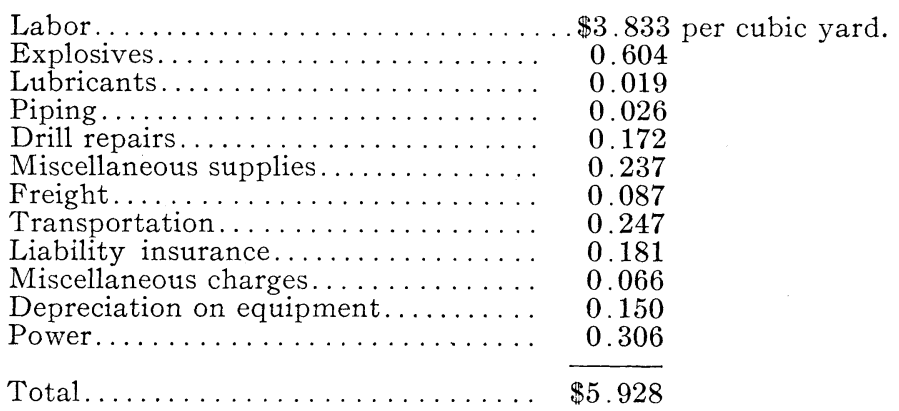

The total excavation for the tunnel amounted to 56,000 cu. yd

The concrete lining of the tunnel called for the placing of $18,966 \mathrm{cu}$. yd. of concrete of a 1-3-5 mixture, the rock not to exceed two inches in size. In considering the best methods for lining a tunnel of this small cross-section, it was decided that steel forms should be used, and it was afterwards decided to place the concrete by a method involving the mixing and transporting of the concrete by compressed air through eight inch diameter spiral galvanized pipe. The concrete when mixed and placed in this manner was at times conveyed as far as $1000 \mathrm{ft}$. from the mixer through the eight-inch pipeand gave very good results as to quality of lining. It was found however that the forms were not of the exactly proper design to facilitate moving, as the space between the rock and the forms was so small as to make their movements difficult. The forms were not designed so that one section could be carried through the other, with the result that unconcreted space had to be left between the various form sections which involved a large amount of difficult bulkheading. It was found that great care had to be exercised to prevent the formation of voids in the lining, this being principally due to its relatively small thickness. A total length of 240 lineal feet of steel forms was used with three pneumatic mixing and placing machines. The side walls and arch were first completed, and then the invertor tunnel floor laid. The progress on the sidewalls and arch amounted to approximately 200 lineal feet per week or $434 \mathrm{cu}$. yd., and the progress in laying the invert was at the rate of $800 \mathrm{ft}$. per week or approximately $544 \mathrm{cu}$. yd. The unit cost of the concrete lining was as follows: 


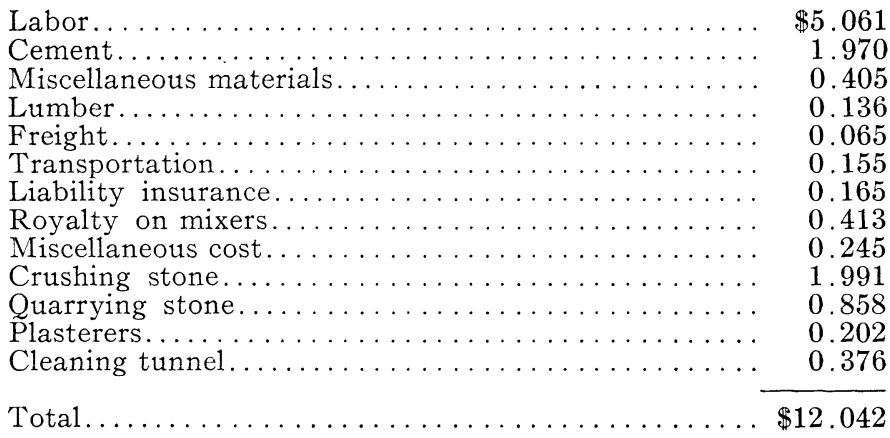

The materials for lining the tunnel were taken in at three places, viz: the forebay, shaft No. 4 , and adit No. 3 , as the rock suitable for this purpose was available at these places. Little of the material excavated in the tunnel could be used for the lining, the adits through which the waste was taken out opening on the gorge side where there was no available space for storage. A quarry was subsequently opened at adit No. 3, and from this point at least 80 per cent of the aggregate material used in the tunnel lining was obtained. All sand used was rolled from the rock so that only the cement and supplies had to be transported.

The specifications called for the entire tunnel to be grouted with grout consisting of one part of cement to $1 \frac{1}{2}$ parts of sand. Grout and vent pipes $1 \frac{1}{2}$ in. in diameter were provided in the tunnel arch at other places where necessary, $15 \mathrm{ft}$. apart, more or less. Four grouting machines were constructed and used with compressed air under a pressure of about $60 \mathrm{lb}$. per sq. in., and no trouble experienced in the grouting except that at some places considerably more material was used than was anticipated would be necessary. The cost of the grouting was $\$ 1.436 \mathrm{cu}$. $\mathrm{yd}$. of concrete lining, made up of the following unit figures:

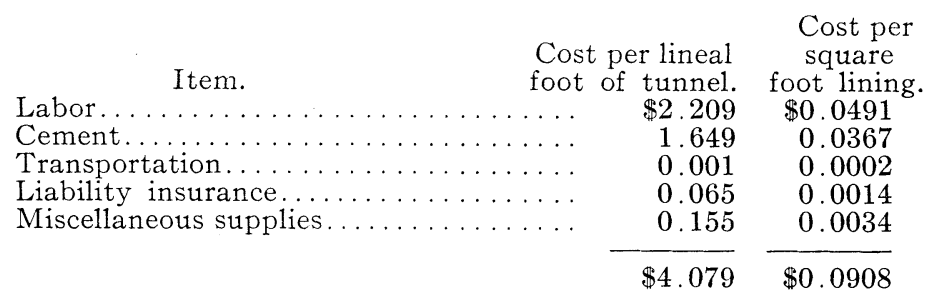

After the completion of the tunnel, two of the adits were closed with concrete barriers, adit No. 3 being fitted with a steel door set in concrete so that future access to the tunnel may be had 
through this adit if desired. Shaft No. 4 was concrete lined and carried some ten feet above the ground and screened over so that access may be had at this point when desired, and also to furnish an additional surge point for the relief of pressure within the tunnel.

The following figures give the approximate total cost of the tunnel per lineal foot:

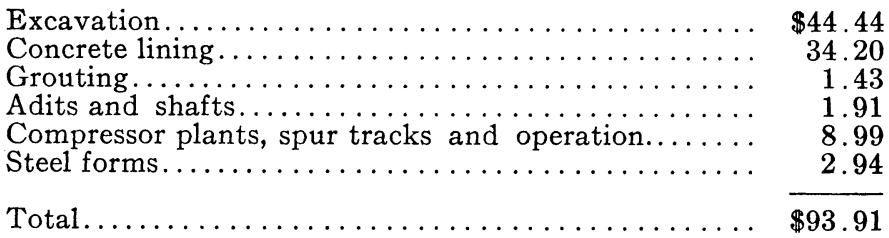

It will be noted that notwithstanding the high cost of the concrete lining, the total cost of the tunnel compares favorably with that of other developments. Fig. 12 shows the completed tunnel.

\section{Forebay}

At the lower end of the tunnel, the forebay, Fig. 13, or surge tank is located, which is of reinforced concrete structure. The reinforcement consists of heavy steel girders and plates, as used in steel building construction, latticed with various sizes of steel rods. There were some 700 tons of steel reinforcement used in the construction of this tank, which was necessary on account of the character of the rock at the location, and the proximity of same to the side of the gorge, this ground not being deemed of sufficient strength to be depended upon in caring for any of the hydrostatic pressure due to a surge or the static condition. The tank was therefore made entirely self contained from a pressure standpoint.

This tank is 30 by $70 \mathrm{ft}$, and $95 \mathrm{ft}$. deep, and was designed to take the entire surge of the water when all of the wheels are shut off under 25 per cent overload.

The excavation at this point involved some $4750 \mathrm{cu}$. yd. of rock, all of which was badly weathered and shattered, the greater portion of it being of such nature that it could not be used in the forebay or tunnel lining. The thickness of the concrete in the tank varies from three to six feet, due to the irregular breakage of the rock sides. As shown in the accompanying sketch (Fig. 13), the tank extends about $64 \mathrm{ft}$. into the rock, the remaining $31 \mathrm{ft}$. of its depth or heighth being above the ground 
line. The tunnel enters the tank a few feet above the bottom at the center of one side, and the six penstocks leave the tank on the opposite side, each of these penstock tunnels being provided with an emergency gate which will automatically break its supporting chain if the penstock should rupture.

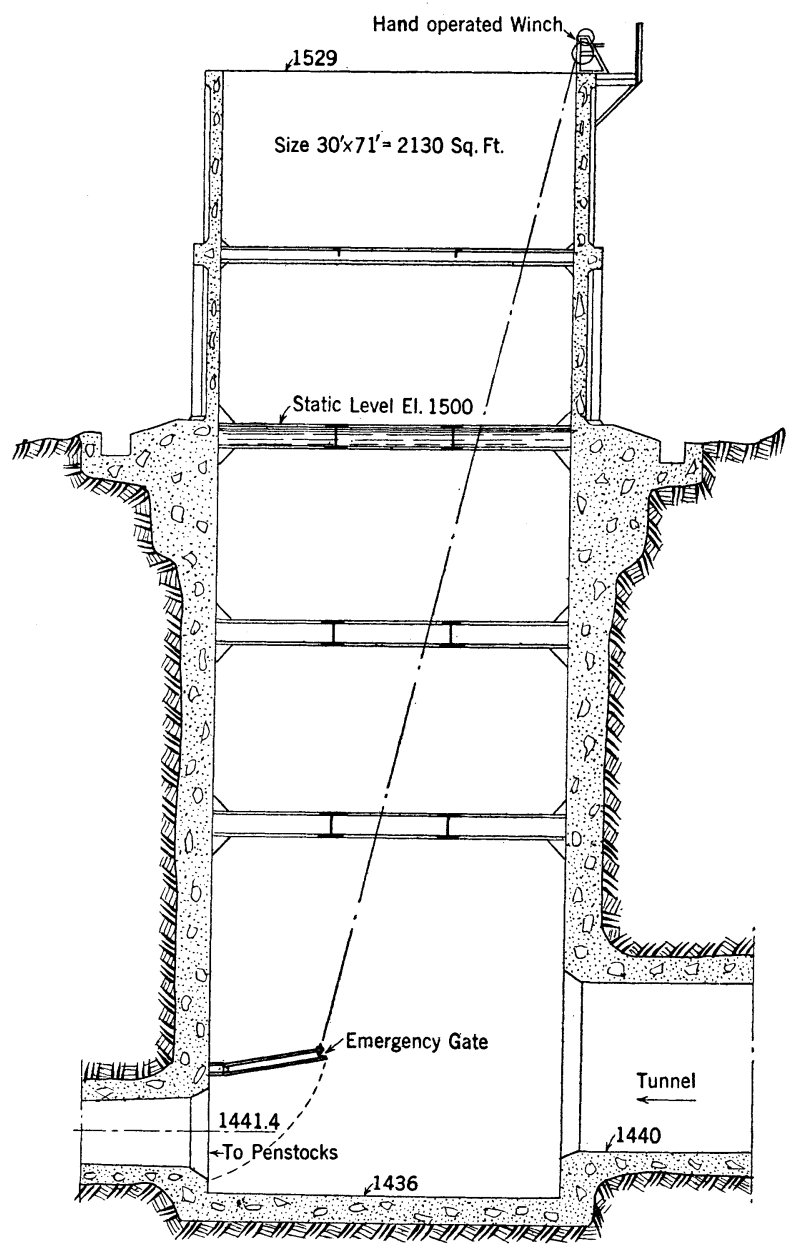

FIG. 13-ForeBAY

The excavating of these six tunnels from the forebay to the side of the gorge was extremely difficult, both on account of their small size and the character of the rock through which they had to be cut. Very light drilling and blasting was necessary in order not to break the rock barriers between the tunnels, which it was 
desired to leave intact because of the additional strength they might give the structure.

After the penstock pipes had been installed in these tunnels, concrete was placed around the pipes filling the space between the pipes and the walls of the tunnels, and then thoroughly grouted under pressure. It was a source of great satisfaction after the forebay had been completed and the water first turned into it that no leaks of any nature were discovered.

The cost of the rock excavation at the forebay was as follows:

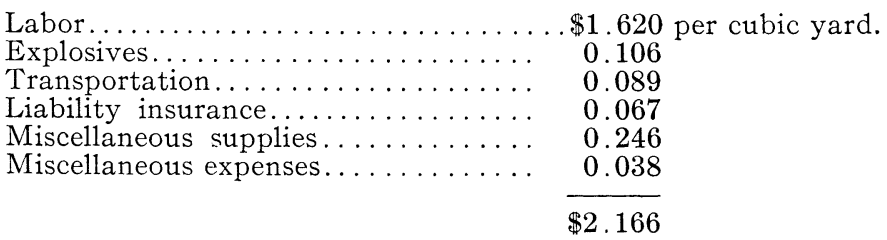

The concrete lining of the forebay shows the following unit figures:

Labor

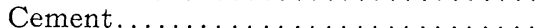

Lumber....................

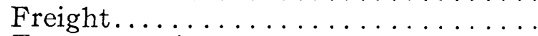

Transportation...............

Liability insurance..............

Miscellaneous expenses........... .

Crushing stone..............

Miscellaneous supplies.
$\$ 1.680$ per cubic yard.

1.920

0.117

0.012

0.013

0.049

0.178

1.569

0.033

$\$ 5.571$

The above figures represent the unit cost of the concrete below elevation 1500. The thickness of concrete was so small and the amount of reinforcement so great in comparison with the concrete below elevation 1500 that no unit cost per yard was made. The concrete used above elevation 1500 cost $\$ 1.925$ per superficial square foot surface one side.

The cost of the steel reinforcing and erection is not given as this depends largely on the market price of the steel, and is exactly the same as in all steel building construction. It should be noted in connection with this structure that with all concrete used below the ground surface, forms were used only on the inside, the concrete coming into intimate contact with the rock outside the steel structure.

Reference to Fig. 14, will show the elevation of the water in the surge tank and the hydraulic gradient corresponding to the various loads on the Tallulah station with the Tallulah 
reservoir at its maximum and minimum elevation. This diagram shows the downward surge caused by an increase of load of 25 per cent and the upward surge caused by the station throwing off a load of $62,500 \mathrm{kw}$., when the storage reservoir is at its maximum elevation. It has been found from tests that these calculations are extremely accurate.

\section{INCLINE RAILWAY}

In order to make possible the transportation and handling of the vast amount of material and equipment from the head of the railroad connection at the forebay to the power house site, and to provide a means of access to the power plant after construction, an incline railway was constructed.

The grade of this road conformed to the hillside as nearly as possible, in order to avoid excessive excavation. It is ap-

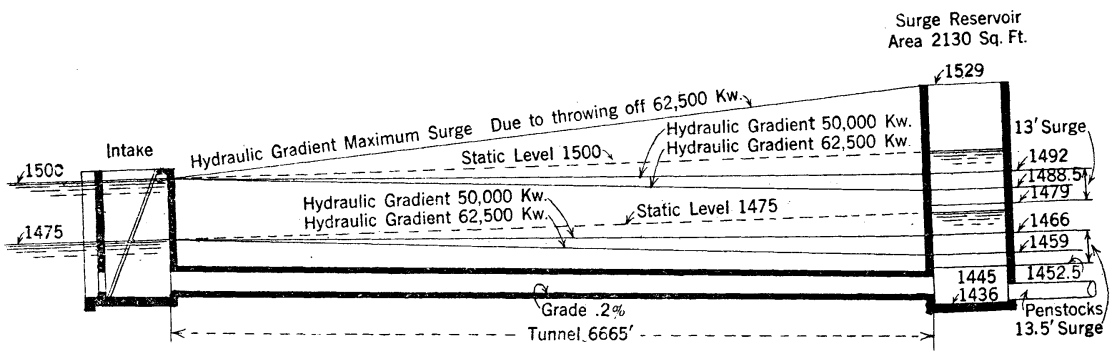

FIG. 14

proximately $1200 \mathrm{ft}$. long and rises in that distance some $650 \mathrm{ft}$., the maximum grade being 98 per cent. At each end of this incline the grade is 85 per cent and a car was provided with a capacity of 50 tons, whose platform is of such angle to the track that on the 85 per cent grade it is level. This car is built of steel throughout, with the exception of the floor, which is of timber. All hydraulic, electrical equipment, building material and steel work of every nature was transported on this car to the power house site without accident either to men or material. This was considered quite a record at the time, as 30,000 tons of material of all nature and approximately 400,000 passengers were handled during the construction period by this railway. The accompanying illustration shows the heaviest piece being transported, Fig. 15.

For the operation of the incline railway a steam hoist was 
provided at the top of the hill to be operated either by compressed air or by a boiler plant which was located nearby. This hoist was also provided with an extension base on which a railway type motor was to be located after the construction period, and the hoist would then operate on energy furnished by the main power plant. This hoist was provided with two heavy cast iron drums and connected to the car by two $1 \frac{3}{8}$-in. diameter special steel wire cables, each of the cables being connected to the ends of a yoke on the car. The car was provided with an automatic cast iron grip connected to the cable yoke and so designed that it would close its jaws, if either cable should break, on a $1 \frac{3}{4}$-in. patent locked wire grip cable laid in the center of the track and thoroughly anchored at the upper end. The ultimate strength of this grip cable as specified, was $260,000 \mathrm{lb}$. There was no cause during construction for this arrangement to operate, since no accident involving the breaking of either hoisting cable occurred. The hoist is arranged to give the car two speeds, that of $60 \mathrm{ft}$. per min. on heavy loads, and of $180 \mathrm{ft}$. per min. when a higher speed is desirable.

The track of this incline railway is built with $80-1 b$. rails, laid on oak ties with a 6 -ft. gage. It was found necessary on the upper and lower $150 \mathrm{ft}$. of the track to lay the ties in concrete, as no material would stay in place on the rock surface. All other portions of this track are heavily rock ballasted; the track being at many points anchored to the underlying stratum. A brick and steel house covers the hoist arrangement at the head of the incline; this house being of similar design and appearance to the power house building. The relative cost of this incline railway will be given in a subsequent table.

\section{Penstocks}

When the penstock installation was first considered, a plan of installing three penstocks, each serving two units, was given considerable attention. It was finally decided to use one penstock for each water wheel in order to give greater flexibility in plant operation and to do away with certain other disadvantages where one penstock served two machines.

There are at present installed five of these penstocks, Fig. 16, each five $\mathrm{ft}$. in diameter and approximately $1250 \mathrm{ft}$. in length; provision being made for the installation of a sixth pipe. It being impossible to bury the penstocks on the hillside, they were carried on concrete piers spaced $32 \mathrm{ft}$. apart, and with heavy 
anchor blocks inserted at all vertical and horizontal bends. Below each of these anchor blocks in all pipes are expansion joints of the packed gland type, with an adjustable angle ring and square hemp packing. These expansion joints were inserted for the purpose of removing the excessive stress due to temperature and other changes of tubes of this large a diameter. The maximum variation of temperature considered in this installation was $65 \mathrm{deg}$. fahr.

In order to allow the penstocks to move freely over the supporting piers, 12 -in curved steel channels were provided under the penstocks at the supporting points; thereby removing the adherence or excessive friction at the concrete contact. These penstocks were placed on 10 -ft. centers and all piers and anchor blocks were carried down and anchored to the solid rock by means of heavy anchor bolts. The five penstocks weigh 1170 tons, of which 565 tons are riveted and 605 tons welded; it being deemed advisable to have welded pipe in the lower portions of the penstocks where the pressure would be greatest. The thickness of the steel plate in the penstocks varies from $\frac{3}{8}$ in. in the upper section to $11 / 16$ in. in the lower portion. There are about equal lengths of each thickness of plate, beginning with the $\frac{3}{8}$-in. plate mentioned and increasing by $1 / 16$-in. steps.

Each section of welded pipe was tested at the manufacturer's shop in Germany with a pressure of one and one half times that to which the pipe would ultimately be subjected. After erection, all field joints were caulked inside and out, and at angle points stiffening angles were supplied for the purpose of anchoring the penstocks in the concrete blocks. An eight inch diameter air valve is provided in each penstock just below the upper gate in order to break any vacuum caused by a too rapid acceleration of the water column in the penstock below. It can well be imagined that considerable difficulty was encountered in placing and riveting these penstocks. As it was done in the summer time it was found impossible to do any riveting on the pipe except at night on account of the heat of the sun, the temperature inside of the pipe rising at times to $170 \mathrm{deg}$. fahr.

The five-ft. diameter of each penstock is maintained throughout its length, with the exception that Venturi meters have been installed just above the switch house for the purpose of water measurement. In the Venturi throats the water channel tapers 
to 35 in. It again resumes the five-ft. diameter until reaching the 45 -in. hydraulic gate valve at the turbine entrance, where the pipe tapers to this diameter. Each penstock is provided with a 60 -in. electrically operated gate valve just outside of the forebay wall. These valves are operated by an electric motor, which is controlled from the power house generator room; signal lights being provided at that point, indicating whether the valve is open or shut. These valves are seldom used and then only at the times when the unit is shut down for repairs or under other circumstances which carry the shut-down over

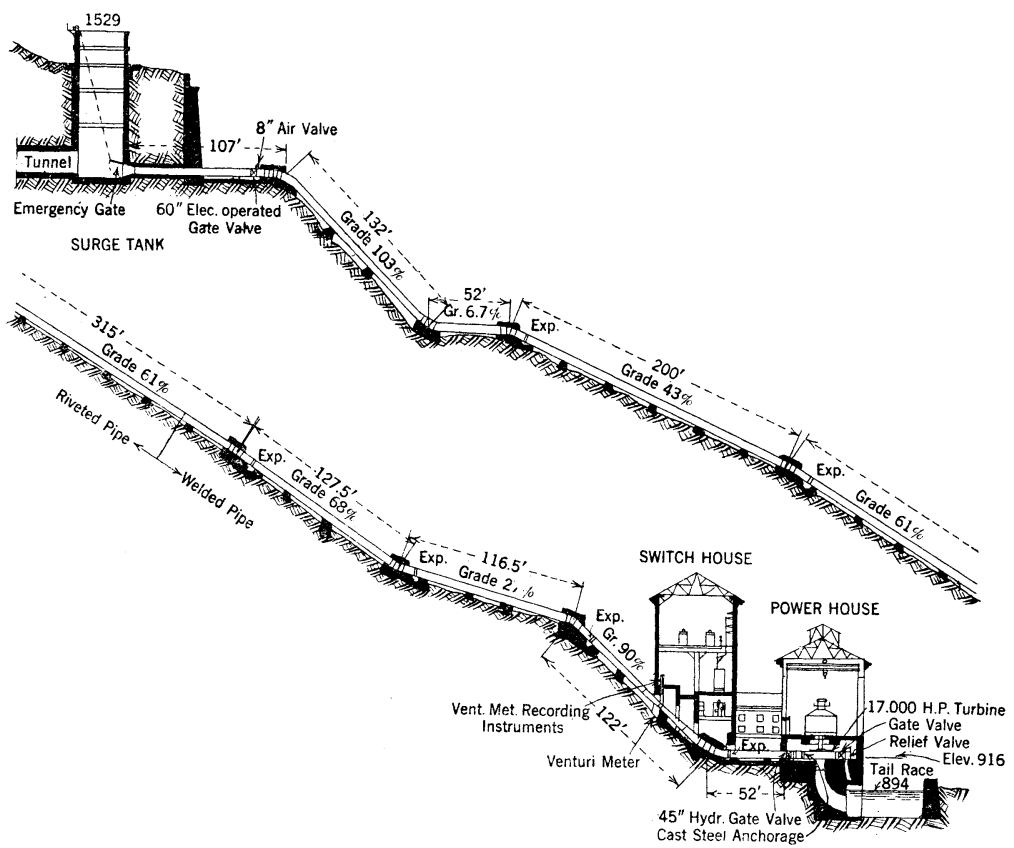

Fig. 17-Profile of Penstocks

several days. The expansion joints mentioned have proved extremely satisfactory, no leaks developing in them, notwithstanding the fact that a maximum movement of two inches has occurred at times.

The preparation of the ground surface for the installation of the penstocks involved a rock excavation of $33,238 \mathrm{cu}$. yd., and the placing of concrete in the anchor blocks and foundations to the amount of $8112 \mathrm{cu}$. yd. With the exception of the concrete adjacent to the power house, all concrete was placed in the penstock foundations from a central plant, the 
PLATE CXLIV.

A. I. E. E.

VOL. XXXIV, 1915

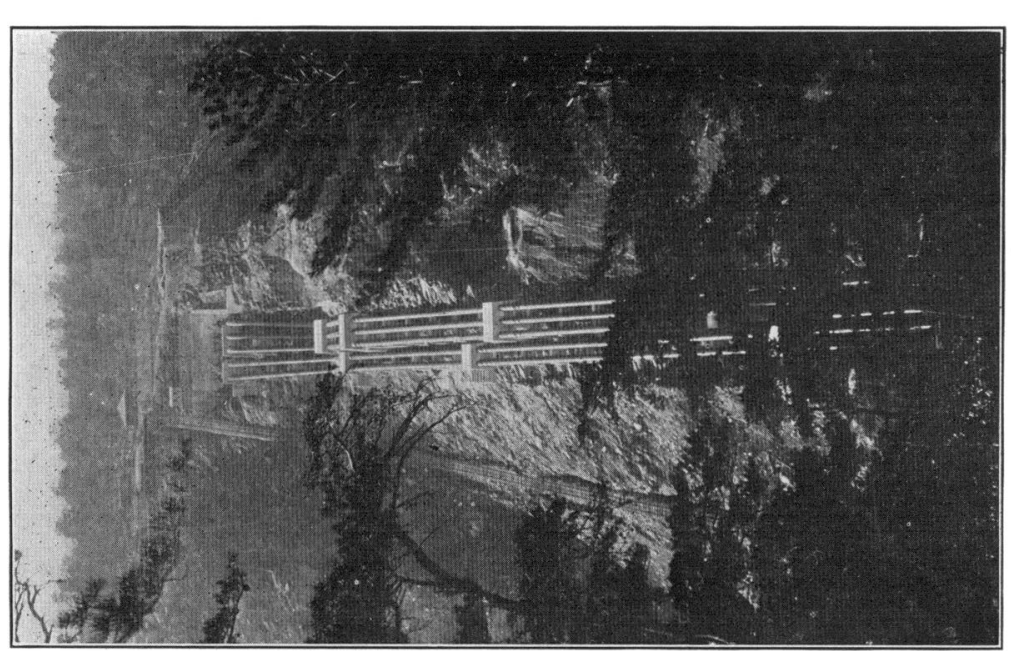

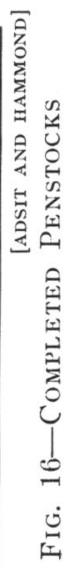

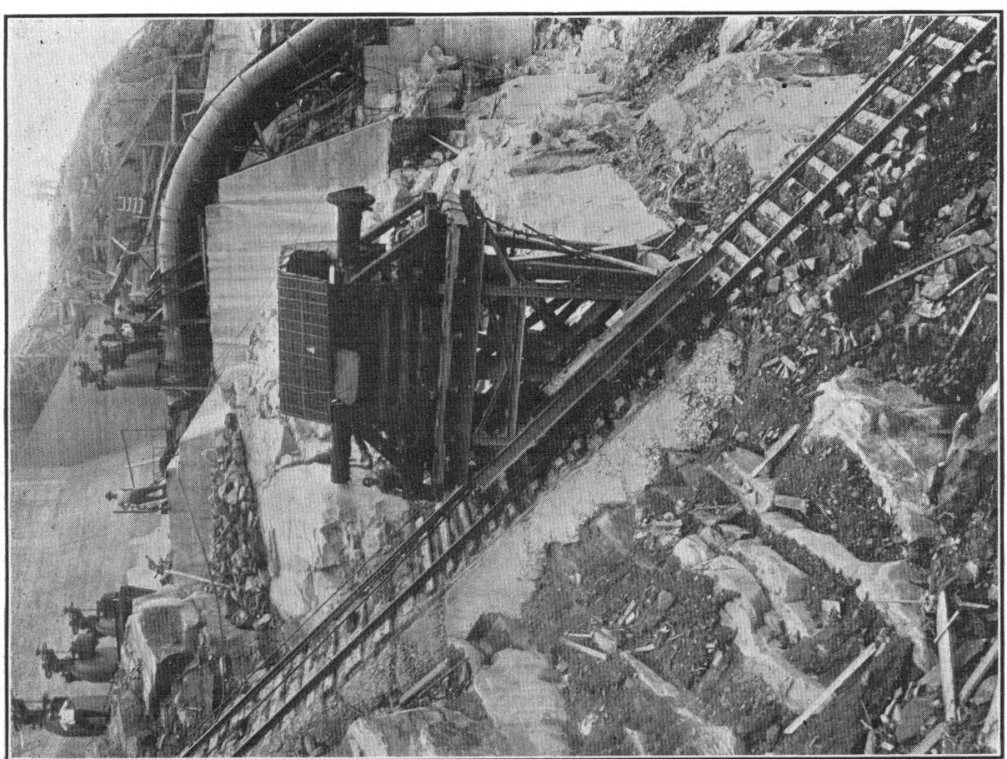

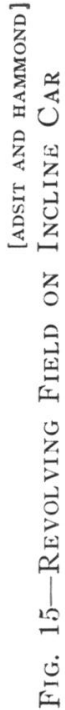


PLATE CXLV.

A. I. E. E.

VOL. XXXIV, 1915

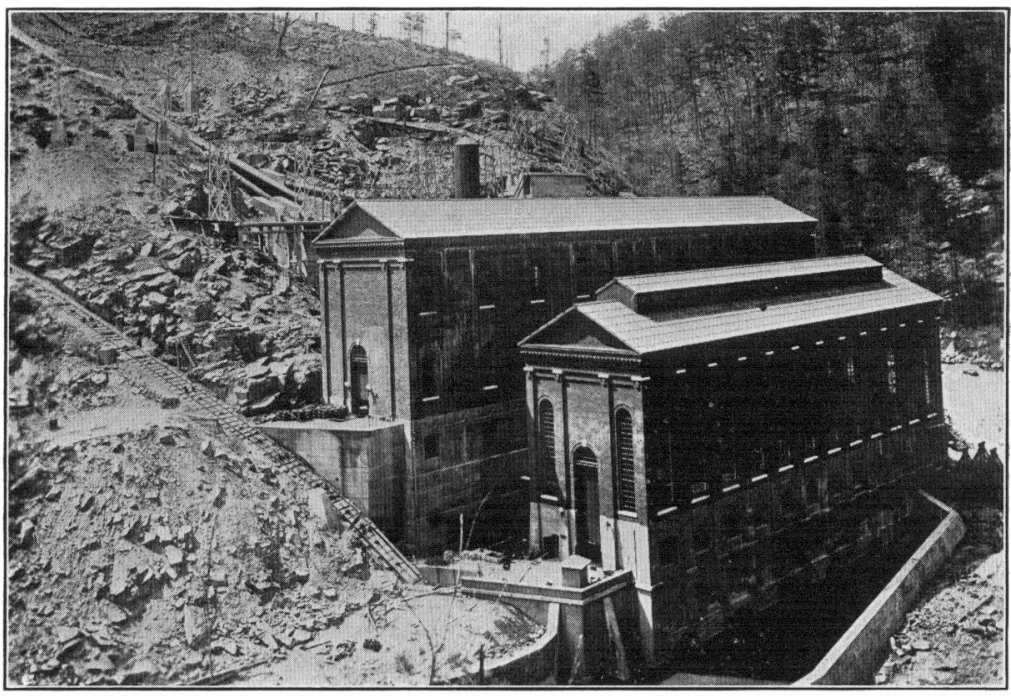

[ADSIT AND HAMMOND]

Fig. 18-Power Plant Buildings

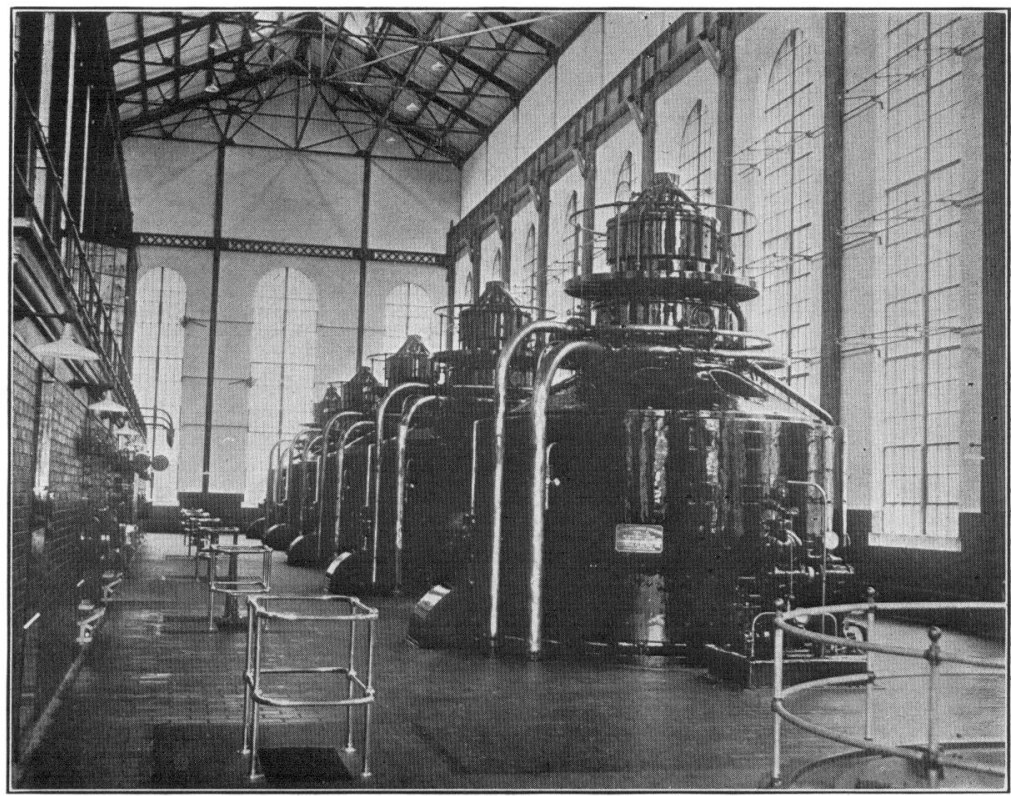

[ADSIT AND HAMMOND]

Fig. 20-Generator Room 
mixed material being carried down in wooden chutes to each block. There were $2231 \mathrm{yd}$. of this concrete placed, under a contract price of $\$ 7.50$ per yard. The remaining 5881 yd. was placed at the following unit cost:

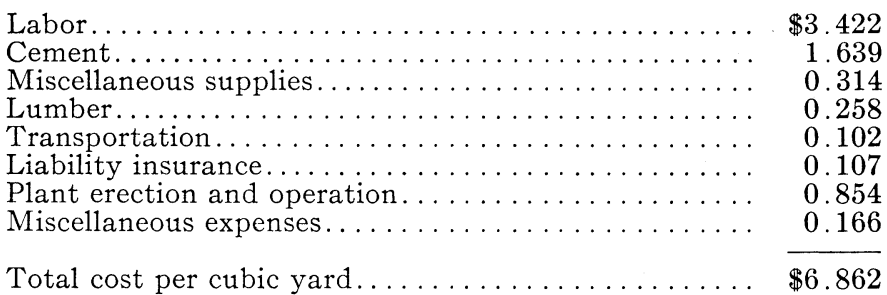

Of the excavation, 13,636 yd. were taken at the contract price of $\$ 1.50$, the remaining 19,602 yd. being taken at the following unit cost:

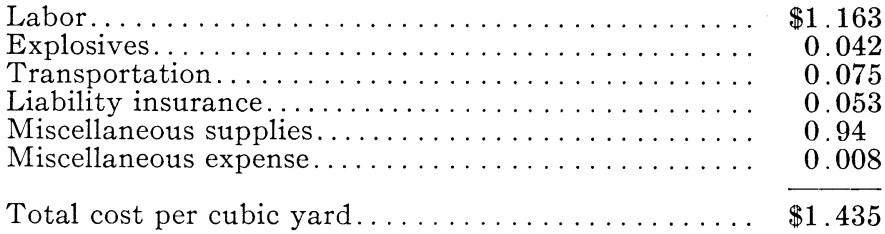

Fig. 17 gives dimension of the penstock and its relation to the forebay and power house.

\section{Power Plant Buildings}

The power plant buildings, as shown in Fig. 18, and in crosssection, Fig. 19, are constructed with a concrete sub-structure, and a structural steel framework enclosed with full brick walls as a super-structure. The roof consists of steel trusses with steel channel purlins surmounted by reinforced concrete slabs, these slabs being interlocked and cemented after being placed. The upper surface is red in color, giving the appearance of tile, and the under surface painted white.

There are two main buildings, known as the generator building and the switch house, which are connected by a small building of the same general type, $28 \mathrm{ft}$. 4 in. long and $20 \mathrm{ft}$. wide. The two main buildings and this small building form a structure resembling a letter $\mathrm{H}$. No wood or inflammable material of any nature has entered the construction of these buildings and they are therefore entirely fireproof.

The generator building, $186 \mathrm{ft}$. long, $42 \mathrm{ft} .3$ in. wide and $49 \mathrm{ft}$. high above the generator floor, is designed to accommodate six 
units on 28 -ft. centers. The concrete sub-structure of the generator building comes up to the window sills in the generator room, and above this begins the super structure. The turbine room is below the generator room floor, and from the turbine floor to the contact with the rock is a solid concrete foundation. Heavy dividing walls separate each turbine bay and support the generator floor, which is of steel framework encased

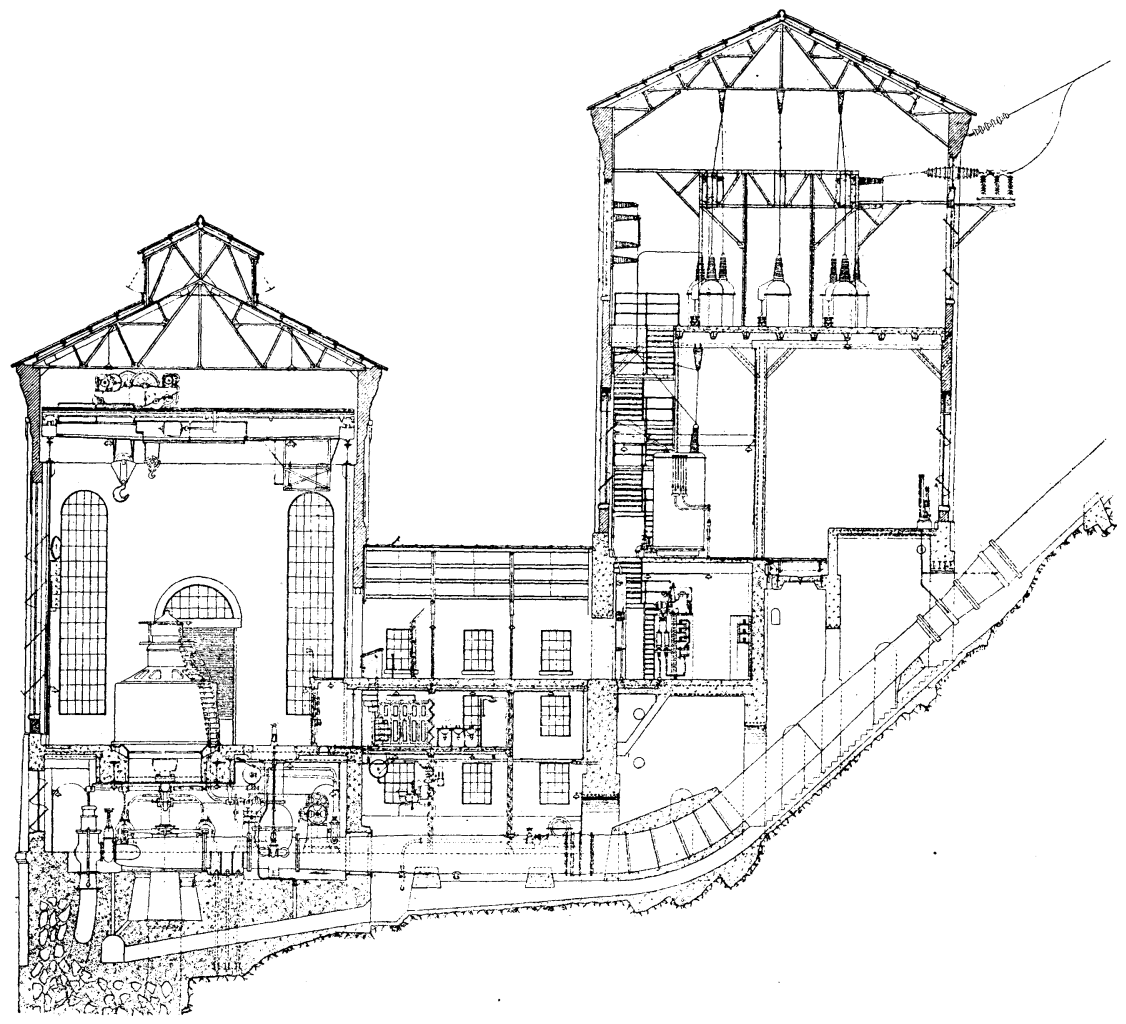

FIG. 19

in a concrete floor approximately five ft. thick. The units are on 28 -ft. centers, with all of the hydraulic machinery, with the exception of the governor head, on the lower floor. This includes for each unit, one 17,000-h.p. vertical hydraulic turbine, two triplex oil pumps, each of 70 gallons per minute capacity, and one oil filter and storage tank from which these pumps obtain their supply of oil. One of the pumps is driven by a direct connection to the main turbine shaft and the other by 
a 35-h.p. 220-volt d-c. electric motor, this motor being supplied with energy from the auxiliary exciter bus. The pumps serve two purposes in connection with the waterwheels; that of lubrication and gate control, the governor on the generator floor actuating by means of oil pressure of $160 \mathrm{lb}$. two cylinders attached to the gate yoke which opens and closes the wicket gate according to the control of the governor action.

The water turbines are designed to operate at $514 \mathrm{rev}$. per min. under an effective head of $580 \mathrm{ft}$., this, by the way, being the highest head under which any turbines are being operated in the United States. The runners of these machines are made of bronze and cast in one piece, 56 in. in diameter, with eighteen buckets or vanes. This runner is bolted to the lower flange of a 14-in. nickel-steel shaft, the shaft being built in two sections, one connected to the water wheel and the other passing through the generator rotor, the two sections being bolted together by means of a faced flange coupling. The scroll case of the turbines is made of cast iron in one piece, and has a 45 -in. inlet with an outlet flange immediately opposite connected to a 20 -in. gate valve which is in turn connected to the hydraulic relief valve. This relief valve is operated by the governor and opens when any sudden reduction in water demand occurs. The 24 wicket gates of the turbine are of forged steel and connected to the operating ring by cast steel shanks. The main journal or guide bearing of the waterwheels is held by the upper cover, and is lined with lignum-vitae strips with end wood towards the shaft. Immediately above these lignum-vitae strips is a chamber which is piped to the water in the penstocks and kept just overflowing during operation. The relief valve mentioned is capable of discharging 70 per cent of the water capacity of the turbines, thus eliminating the water hammer and excessive pressure in the penstocks due to any load being suddenly removed from the machines.

The turbines are set directly over the entrance to the draft tube, which is $40 \mathrm{in}$. in diameter at the upper end and eight feet at the outlet.

All of this equipment was tested under $400 \mathrm{lb}$. pressure per sq. in. before it left the manufacturers shops. The governor cylinders which operate the gate mechanisms are capable of exerting $60,000 \mathrm{ft}-1 \mathrm{~b}$. of energy in this operation. They are mounted on base plates which are secured to the scroll case and bolted to the concrete floor. The entire scroll case is sub- 
merged in the concrete foundation to half its diameter. The specifications for the governor control called for a speed variation for $25,50,75$ and 100 per cent variation in load not to exceed $3,7,13$ and 20 per cent respectively, above or below normal. It was also specified that the flywheel effect of the generator rotor would be $1,250,000 \mathrm{ft}$. $1 \mathrm{~b}$., and it has been found during operation that the speed regulation under these circumstances is much better than that specified. While no accurate percentage has been obtained, it has been noted that full load may be thrown off the machines without any noticeable increase in speed.

The 45-in. gate valve is placed in the penstock line just ahead of the heavy cast steel anchor piece which is in turn connected to the turbine. This gate valve is hydraulically operated, controlled from the generator floor, and has a control cylinder $26 \frac{1}{2}$ in. in diameter, with cast iron piston and bronze covered gate stem.

The water discharged from these turbines enters the tail race which is tapered from $10 \mathrm{ft}$. at the upper end to $50 \mathrm{ft}$. at the lower end, and is protected from the river by a solid concrete wall extending from the first unit upstream to $100 \mathrm{ft}$. below the power house proper. Installed in this tail race at the lower end is a submerged concrete wall which was fitted with anchor tubes and bolts for the purpose of erecting a weir thereon at any time it may be desired to accurately measure the discharge of water from the machines. In addition to this weir, and in service constantly, are Venturi meters connected through a system of piping and valves to each penstock. This meter installation consists of one meter and recording device, and four manometers which can be connected to any penstock desired.

In addition to the five main waterwheels there is installed a 75-h.p. Pelton wheel driving a 50-kw. exciting set, this wheel being placed in the sub-structure of the small building, and serving as a small station pick-up set or exciter as desired.

\section{Generators}

The generator equipment, Fig. 20, as installed at present consists of five main units, each rated at 12,000 kv-a. maximum, at 6600 volts. They are three-phase, 60 -cycle revolving-field type, very similar in design to vertical steam turbine units. These machines are guaranteed, when operating at 80 per cent power factor to have a temperature rise not exceeding $40 \mathrm{deg}$. 
cent., or at 25 per cent overload for two hours, not above 55 deg. cent. It has been found in operation that these temperatures are not reached under the above conditions. They have a guaranteed efficiency under full load of 95.5 per cent, which has been considerably exceeded under tests. All the guarantees on these machines were based on a $10,000-\mathrm{kw}$. rating, but their performance under operation was such that they were re-rated to $12,000 \mathrm{kw}$. maximum, for the reason that not only were they good for this load on continuous run without the temperature rise exceeding the specifications for $10,000 \mathrm{kw}$., but it was also found that the waterwheels could be re-rated to 17,000 h.p., thus conforming to this additional generator capacity.

The revolving field structure is made up of steel disks bolted together with the field pieces dove-tailed thereto. They are designed to withstand a runaway speed of 1.7 times normal for one hour. The field coils are wound with strip copper on edge and insulated sufficiently to meet this requirement; heavy spacing and end blocks are provided for each coil to prevent the windings from bulging under this high speed.

The generator has two guide bearings and also carries the thrust bearing supporting the entire revolving weight. This bearing is of the ordinary disk type and is supplied with oil at 150 pounds pressure. It is supported by the generator housing just below the exciter, which is also carried on the same support, the exciter armature being bolted to the upper end of the generator shaft. The over-all diameter of the generator is $13 \mathrm{ft} .8 \mathrm{in}$. and the height from floor to top of exciter $17 \mathrm{ft} .8 \mathrm{in}$., the total weight without the shaft being 76 tons.

Each generator, as already indicated, is surmounted by a sixpole, compound-wound, commutating-pole exciter direct-connected to the generator shaft and having a rating of $100 \mathrm{kw}$. at 250 volts, with 25 per cent two-hour overload capacity. Each exciter is capable of exciting two generators and provisions are made in the switching arrangement so that any exciter may be operated in parallel with the others on the field bus or connected to an auxiliary power bus. These exciters are controlled by a two-unit voltage regulator, thus providing a means of operating the station on two independent power services.

The wiring from the exciters is carried down the inside of the generators between the laminations and the cast armature ring, and is connected to the main exciter switchboard by cables laid in fiber conduits, which are in turn laid in the concrete of 
the generator floor. The power current of the generators is connected through a similar system of conduit by means of cables directly to the oil switch equipment in the switch room, no a-c. switching of any nature being done in the generator building.

The armature windings of the generators are $\mathrm{Y}$-connected, the neutral being carried to a system of switches whereby only one generator may be grounded at one time.

The ventilation of these machines is forced by means of fans on each end of the revolving field, which cause a flow of $35,000 \mathrm{cu}$. ft. of air per minute. This air is taken from the waterwheel floor and discharged through the generator air passages opening into the generator room.

The generator room is provided with a 60 -ton electric crane travelling the entire length of the building. This crane is also fitted with an auxiliary hoist of 15 tons capacity mounted on the same carriage as the main hoist. It is supplied with d-c. energy at 250 volts from the auxiliary exciter bus.

The generator room is also provided with a gallery, as shown in Fig. 20, $155 \mathrm{ft}$. long, which encloses all field rheostats, exciter and auxiliary buses, and exciter switchboard, this switchboard being on the same level with the generator room floor.

\section{Switch House}

The switch house is a building similar in construction to the main building and is $244 \mathrm{ft}$. long, $46 \mathrm{ft}$. wide and $103 \mathrm{ft}$. high from the first floor to the lower cord of the roof trusses, inside dimensions. It is so situated on the hillside that the lower outside wall is $15 \mathrm{ft}$. higher than the one next the hill side. This building is substantially provided with three floors, the first floor containing all low-tension switches, transfer buses, etc., the second the power transformers, and the third all hightension switching equipment.

Referring to the accompanying wiring diagram of the power house, Fig. 21, it will be noted that the generators are connected through low-tension oil switches on the first floor of the switch house to the transformer deltas on the floor above by two 1,000,000-cir. mil varnished cambric-insulated single-conductor cables for each phase, carried in fiber ducts, these ducts being supported in passing from the generator building to the switch house by means of small reinforced concrete bridges. The switching arrangement is so designed that each generator may 
be connected so its respective transformer bank, or connected to a transfer bus running the entire length of the building to supply any other transformer bank, and to multiple the generators on the low-tension side. There are three low-tension switches to each unit, the generator and transfer bus switches being non automatic of 1200 amperes capacity. The transformer switches are of the automatic type, and are provided with inverse time limit relays, so arranged that they will trip both the low-tension and high-tension transformer switches

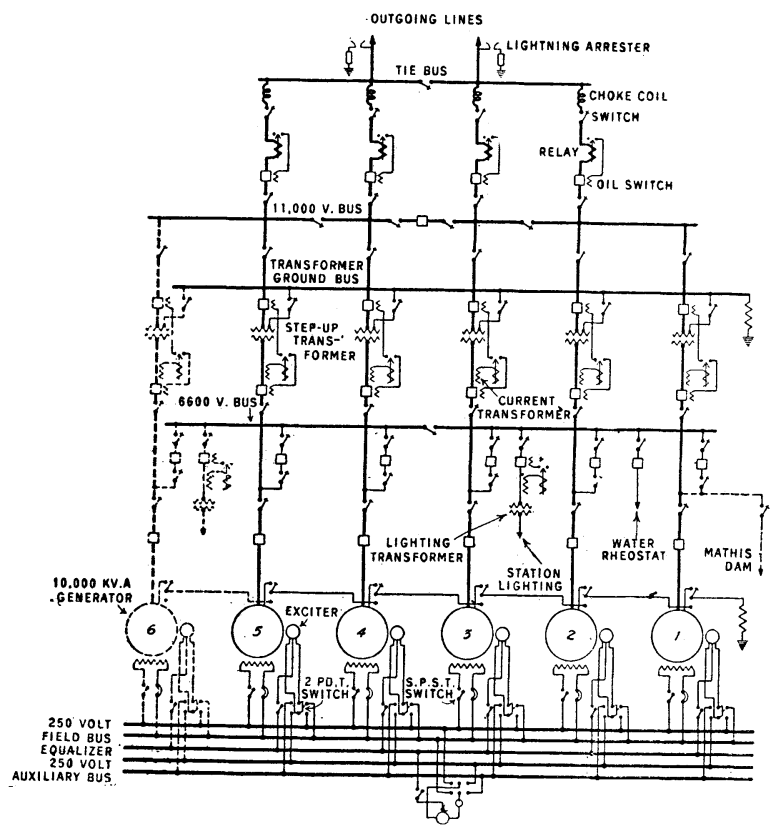

FIG. 21

simultaneously. These relays are energized from three 1500ampere current transformers inserted in the transformer connections, and housed within the concrete barriers in the lowtension switch room. All of the low-tension 6600-volt oil switches are of the remote control, motor-operated type, and each phase separately enclosed in a brick compartment with brick barriers. The switches and operating mechanisms are supported on soapstone slabs built into this brick structure. Disconnecting switches are also inserted in each lead, and located in this brick structure for the purpose of isolating the 
switches in case of repair. The transfer bus, running the entire length of this lower floor, is also enclosed in a brick and soapstone structure.

All high-tension wiring consists of one-in. copper tubing spaced eight ft. between phases, and mounted on porcelain insulators. The high-tension bus runs the full length of the upper switch room, and is sectionalized in the center by a bank of oil switches. Each of these sections is again sectionalized by means of disconnecting switches of the ordinary open air type, which provides each of the four high-tension outgoing lines with an individual section of this high-tension bus.

The high-tension oil switches in this room are of the solenoid operated type, each switch being single pole, double break, single phase, so that three are installed in each unit and operate simultaneously. They are installed in this switch room, one bank of switches for each transformer, one bank for sectionalizing the high-tension bus, and four banks in the outgoing lines, making a total of 10 banks or 30 separate switches, which is said to be the largest number of 110,000 -volt switches installed in one room in service in this country. One of the accompanying illustrations, Fig. 22, shows a general view of the arrangement of switches in this room.

The outgoing line switches are provided with inverse time limit series relays mounted on post insulators just above the switches.

It may be interesting to state at this point that one bank of these outgoing line switches has opened under an energy load of $27,000 \mathrm{kw}$. without spilling the oil or causing the slightest disturbance.

All of the high-tension switching equipment and wiring is designed for 110,000 -volt operation, but has frequently been subjected to an operating condition demanding 130,000 volts at this station without the least injury.

\section{The Control Board}

The operation of the entire station is carried out from the control board on the upper floor of the small building connecting the two larger ones, and consists of the ordinary benchboard controlling all oil switches of the remote control type, the water wheel governors, exciters, main generator rheostats and voltage regulators. It is also fitted with signal buttons enabling the operator to advise the waterwheel and generator 
PLATE CXLVI.

A. I. E. E.

VOL. XXXIV, 1915

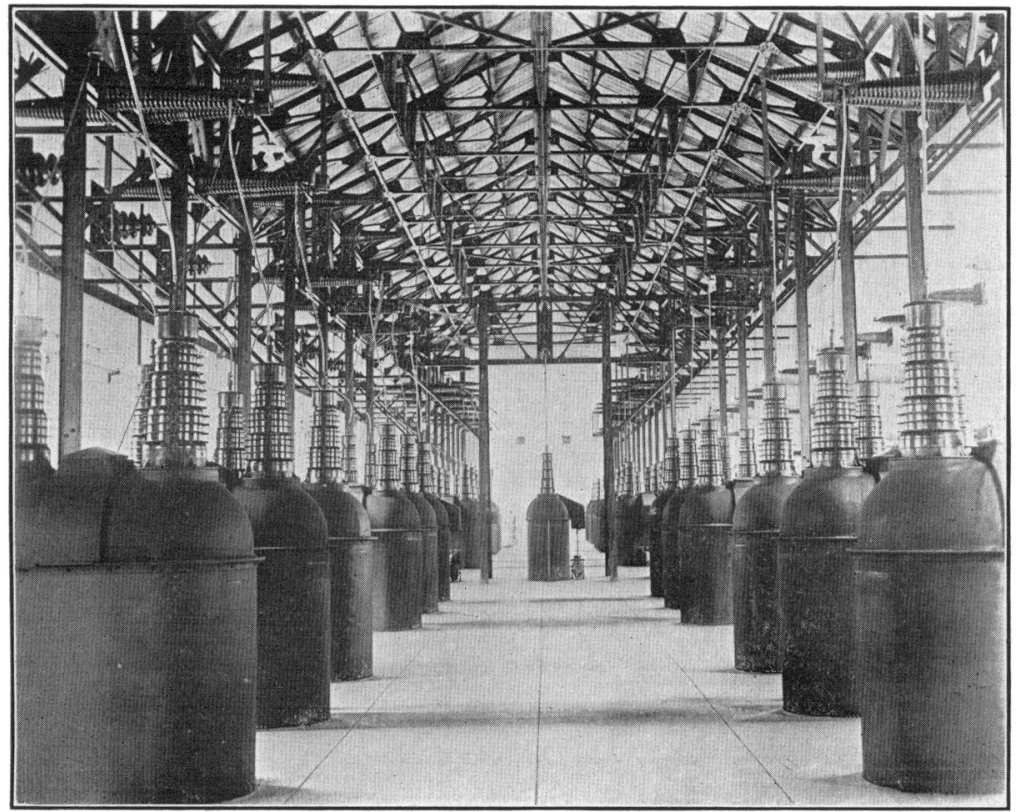

[ADSIT AND HAMMOND

Fig. 22-High-Tension Switch Room

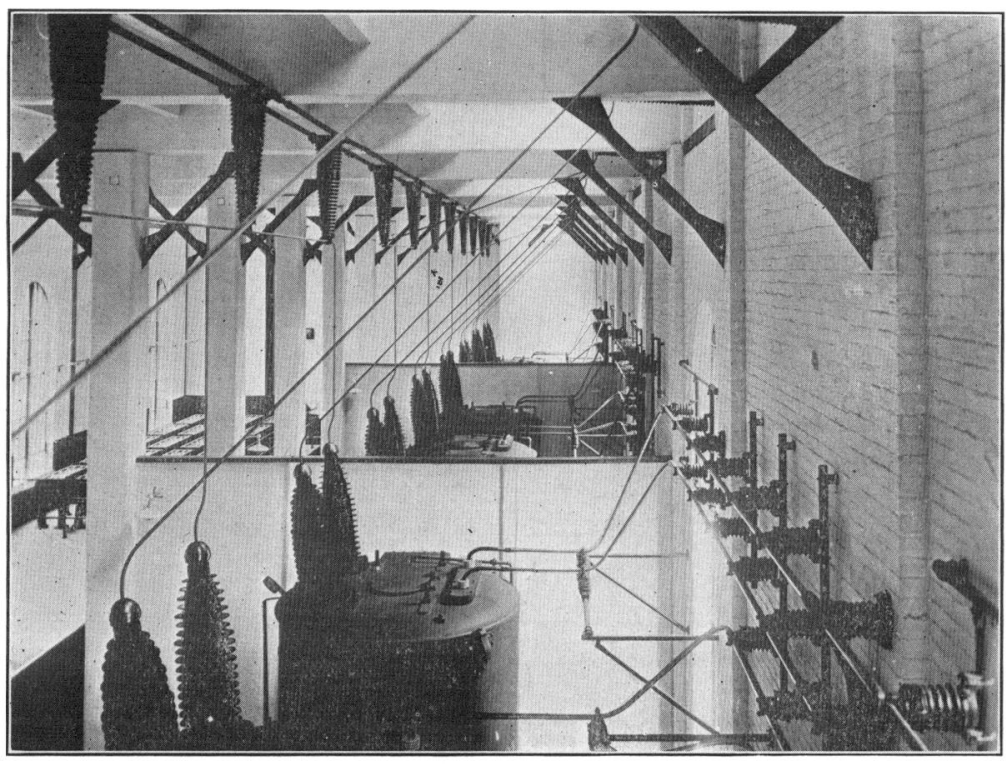

[ADSIT AND HAMMOND]

Fig. 23-Transformer Banks 
PLATE CXLVII.

A. I. E. E.

VOL. $X X X I V, 1915$

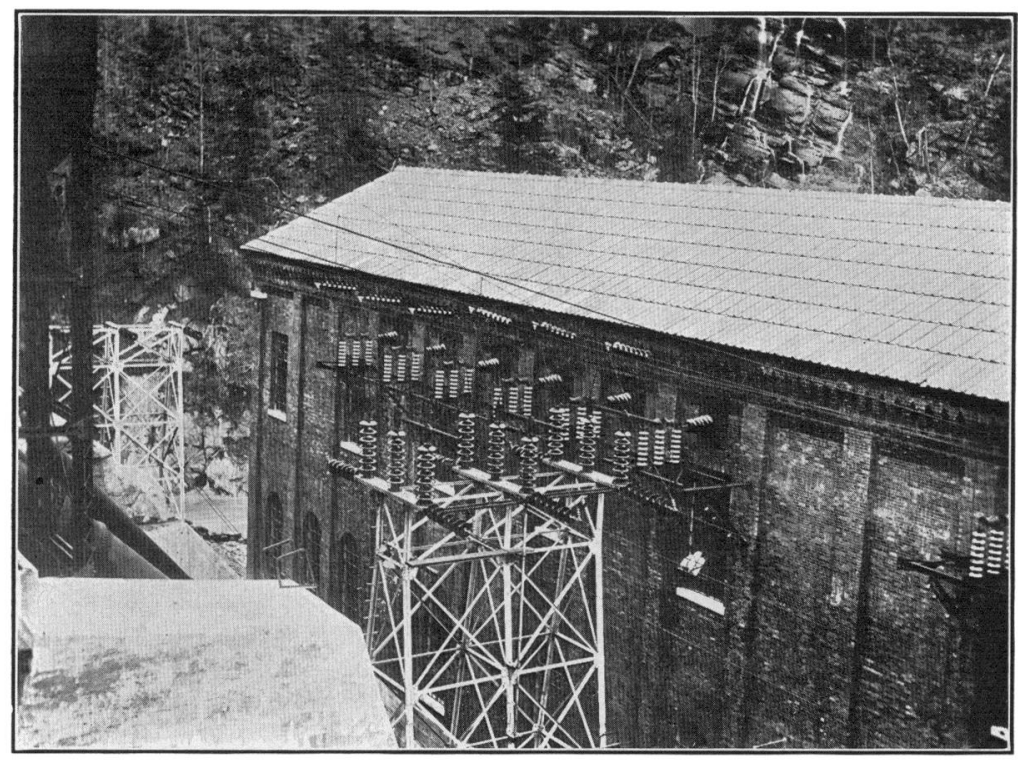

[ADSIT AND HAMMOND]

Fig. 24-Entrance Bushings

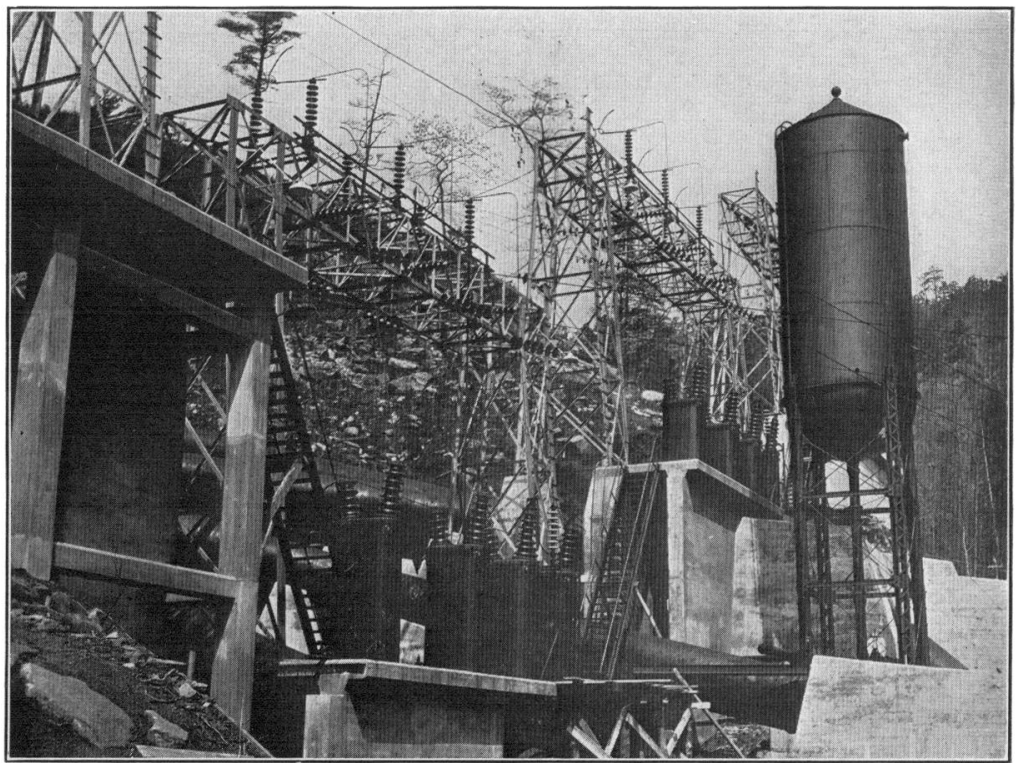

[ADSIT AND HAMMOND]

Fic. 25-Lightning Arrester 
attendants of his desires in connection with the starting or shutting down of any machine. Immediately behind this benchboard is a six-panel black slate instrument board, on which all electrical instruments are mounted. In addition to the usual voltmeters, frequency indicators, power factor indicators, ammeters and recording instruments, a device has been installed whereby any line disturbance causing a permanent or temporary ground is brought to the attention of the switchboard operator by means of relay operating flash lamps and a recording ammeter. These instruments are connected to current transformers in the grounded neutral of the high-tension leads. The relay is designed to make sufficient noise to attract the operator's attention should he fail to notice the lamp signals. This instrument has been found to record any flash-over of the line insulators, and almost every other disturbance which occurs on the high-tension lines. It gives the operator in many cases advance information of coming trouble.

\section{TRANSFORMERS}

Corresponding to each of the five generators is a bank of single-phase, water-cooled, oil-insulated, shell-type transformers, each bank being separated from the adjacent banks by reinforced concrete fire walls, Fig. 23. Each of these transformers has a normal continuous rating of $3333 \mathrm{kv}$-a. with a temperature rise within $40 \mathrm{deg}$. cent., and a 25 per cent two-hour overload capacity with a temperature rise within 55 deg. "cent., based on a supply of 15.7 gallons of cooling water per minute, with an efficiency of 98.7 per cent.

The water for these transformers is supplied through a piping system running the full length of the switch house, from an elevated tank above the main buildings, which is in turn connected through an automatic filling valve to the penstocks.

The low-tension 6600-volt windings of these transformers are delta-connected, while the high-tension windings are starconnected, the arrangement giving a transmission voltage of 110,000 volts. The high-tension windings are accordingly designed for 63,500 volts. The neutral lead from all banks is connected through open air disconnecting switches to a main ground bus, which is grounded through 127 ohms current limiting resistance. These transformers are furnished with three 5 per cent taps, corresponding to voltages below normal of $60,300,57,200$ and 54,000 . They were all submitted to a test 
of 220,000 volts for one minute between primary and secondary, and primary and core. The tanks are cylindrical in design, built of steel plate with cast iron covers. They are mounted on trucks which can be moved to any part of the switch building by means of a transfer truck onto which the smaller truck supporting each transformer can be rolled.

Each transformer requires approximately 2800 gallons of insulating oil, and a system of piping has been installed whereby this oil may be taken from any transformer, filtered and returned thereto without necessarily taking the transformer out of service. A quick-opening valve is provided at the bottom of each transformer and connected to a system of discharge piping outside the building through which the transformers may be quickly emptied of oil in case of fire. Each transformer is provided with thermometer equipment fitted with contact making device for operating an alarm bell in the control room in case of any temperatures reaching a dangerous value.

These transformers are eight feet in diameter, $13 \frac{1}{2} \mathrm{ft}$. high to the top of the cover, and $16 \mathrm{ft} .6 \mathrm{in}$. to the top of the hightension leads, each single-phase unit weighing complete with oil 23 tons.

\section{OUtgoing Lines}

The high-tension leads leaving the building are carried through built up porcelain insulating shells attached to the steel framework of the building and filled with insulating oil, Fig. 24. There are four outgoing lines, the three leads of each, after leaving the building, being connected through choke coils mounted on a steel framework bracketed to the steel work of the switch house. Immediately behind the switch house is a paralleling high-tension bus in four sections supported on steel framework resting on a concrete base, one of the outgoing lines being connected to each section, and open air disconnecting switches installed between the bus sections. The outgoing lines then pass to the lightning arrester structure, Fig. 25, this structure being likewise of galvanized steel framework supported on concrete foundations, the lightning arrester equipment consisting of four-tank, aluminum-cell, three-phase 110,000volt arresters, three of the tanks being connected through the horn gap switches to the separate phases of the line, and the fourth tank between the common terminal of the other three and ground. Four sets of such equipment have been installed, one on each line. 


\section{Station Service}

The station lighting service is supplied from the low-tension bus through two banks of three $20-\mathrm{kw}$. single-phase transformers, stepping the voltage down from 6600 volts to 230 or 115 volts. This lighting service may also be supplied from the exciter or auxiliary buses, or if the station is entirely shut down, from the 75-h.p. Pelton waterwheel set previously mentioned.

The alternating-current service also supplies power to a motordriven air compressor, the air being piped throughout both buildings with service connections opposite each piece of electrical apparatus so that it may be used for cleaning and other station service.

A ground bus has been carried through the cement floors of the power house buildings and connected to every electrical piece of apparatus in service. It is also connected to the steel building structure at various points and to the cast iron housings of the entrance bushings, every precaution thus being taken to insure the grounding of all parts with which the operators might come in contact. This ground bus is connected to a separate ground other than that of the high-tension arresters.

The unit cost of the power house buildings and installed equipment is given in the following tables, the cost of the hydraulic and electrical equipment being based on the installed capacity of $50,000 \mathrm{kw}$. on the original rating and that of the buildings and other equipment on $60,000 \mathrm{kw}$., the ultimate capacity of the original rating.

Buildings AND Foundations:

Rock excavation.......

Concreting foundations and substructure................ 2.114

Structural steel............. 0.522

Handling and unloading......... 0.030

Erecting................. 0.109

Brick, sand and cement......... 0.460

Handling, mixing and laying...... 0.960

Windows and doors............ 0.176

Handling and erecting............... 0.003

Tile roofing.................. 0.115

Concrete tile floors........... 0.400

Miscellaneous material......... 0.186

Miscellaneous labor and transportation of men............. 0.234

Painting.................. 0.124

Plumbing............... 0.053

Building inspection. . . . . . . . 0.142

TAIL RACE:

Rock excavation............. 0.197

Cribbing................. 0.017

Concreting tail race walls........ 0.242

Total................ $\overline{\$ 6.512}$ 


\section{Equipment:}

Hydraulic equipment........\$6.582 per kilowatt

Handling and erecting......... 0.463

Electrical equipment and erection. . . 6.236

Auxiliary equipment........... 0.999

Handling and erecting auxiliary equipment................ 0.105

High- and low-tension switch and bus structure.............. 0.445

Water and oil piping system....... 0.244

Total equipment..........\$15.074

Grouping the above items under a more condensed form, we have:

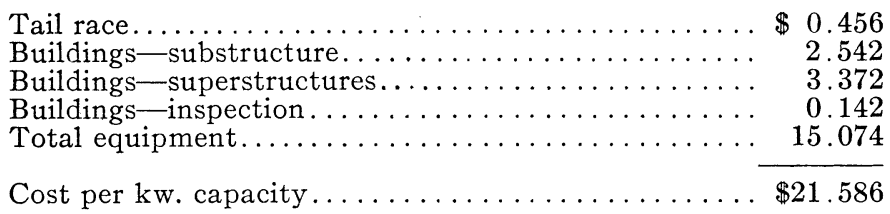

In addition to this cost there is a certain proportion of the temporary compressor plant, spur tracks, general tool and utility equipment, etc., amounting to $\$ 1.178$ which should be charged to this power plant construction, making the total cost of the power plant buildings and equipment $\$ 22.764$ per kilowatt capacity.

As the foregoing costs do not in some instances give the cost of completed structure under the various headings, the following table will supply the construction cost per kilowatt capacity of the entire power production plant, including reservoirs, dams, all hydraulic conduits, power plant and equipment, and including temporary construction plant, such as compressor plants, water system, spur tracks, etc.

Mathis dams and reservoirs.........\$17.104 per kw.

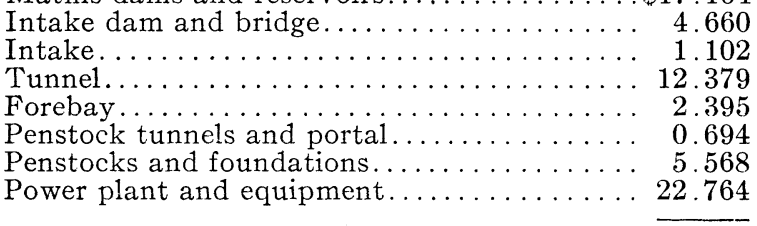

Total construction cost, power production plant, per kilowatt............\$\$66.666

\section{Transmission Lines}

As already pointed out in the beginning of this article, the power house at Tallulah is connected with the main distributing 
station at Atlanta, known as the Boulevard station, by a doublecircuit steel tower line.

The towers, Fig. 26, on this line are of the four-legged construction, $66 \mathrm{ft}$. in height, $20 \mathrm{ft}$. square at the base and $5 \mathrm{ft}$. at the top or basket portion of the tower, and weigh $5554 \mathrm{lb}$. The towers are fitted with four channel iron crossarms of such lengths as to support the two circuits from the ends of these arms with a clearance of $16 \mathrm{ft}$. between the two circuits, or $5 \mathrm{ft} .6 \mathrm{in}$. between either circuit and the tower. This tower is known as the standard $4 / 0$ tower to distinguish it from another type of heavier construction which is used as an angle tower on the same line. This latter tower weighs 6880 lb. The specifications governing the design of the standard 4/0 tower were as follows:

Case 1. A pull of $4300 \mathrm{lb}$. at right angles to the end of any one crossarm, representing the stress due to the deadending of one conductor.

Case 2. A vertical load of $1500 \mathrm{lb}$. at the end of any or all crossarms to cover the weight of the wire and insulators in adjacent spans.

Case 3. A load of $1500 \mathrm{lb}$. in any direction at the top of the tower corresponding to the wind pressure on the projected tower area.

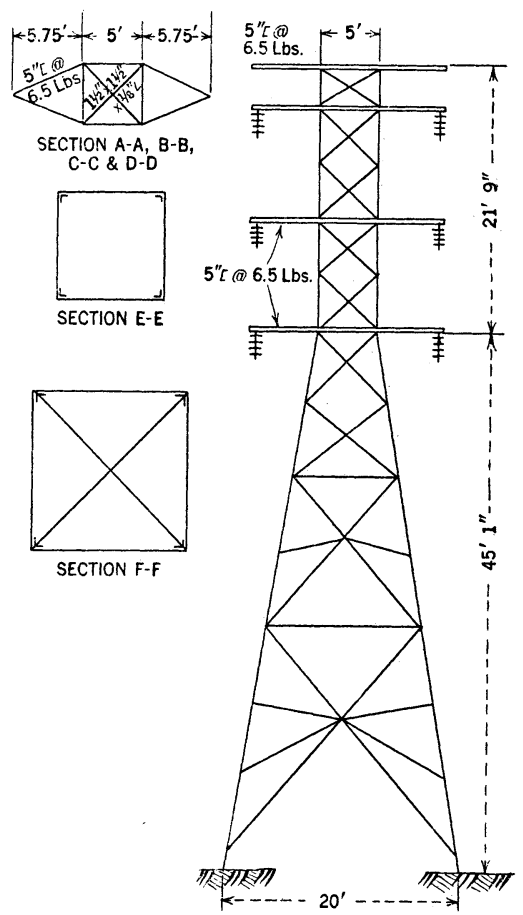

Fig. 26-Standard 4-0 Tower

Case 4. A load of $10,000 \mathrm{lb}$. at right angles to the line or parallel to the crossarms; that is, $2500 \mathrm{lb}$. at each crossarm; at the same time a pull parallel to the line or at right angles to the crossarms of $8000 \mathrm{lb}$., that is, $4000 \mathrm{lb}$. in the same or opposite directions at the end of any single crossarm, or at one end of any two crossarms. The first conditions represent the stress due to wind pressure on the projected area of the crossarms and wires themselves, and the second the stress caused by the breaking of two wires, one on each side of the 
crossarm at different ends, resulting in a couple which sets up torsional strains in the tower.

The crossarms are proportioned for a combination of cases 1 and 2 , and $1250 \mathrm{lb}$. horizontal thrust at the end of the arm. The tower is proportioned for the maximum combination of cases 2 and 3 or 2 and 4 .

The footings for the regular straight line towers were secured by extending the tower legs some seven feet into the ground and bolting cross angles to them. On strain and angle towers, concrete footings were provided, and the tower legs secured fastened to these footings.

The towers on this line are spaced from seven to eight per mile, and as stated carry a double circuit transmission line. Each circuit consists of one $7 / 16$-in. steel strand ground wire and three $4 / 0$ copper conductors, made up of seven strands of hard drawn copper with a central strand of soft drawn. All four wires of each circuit are arranged in a vertical plane with 9 -ft. spacing between the power conductors and $3 \mathrm{ft} .4 \mathrm{in}$. between the ground wire and upper conductor immediately below.

The ground wires are fastened to the ends of the upper crossarms by means of a specially designed steel clamp, and the power conductors suspended from the ends of the other three or lower crossarms by means of two part suspension insulators, with four units in series on straight line towers and five on strain towers. Strain towers are provided for anchoring the conductors every mile, and also on both sides of all railroad, telephone line or other power line crossings.

From the Boulevard station to what is known as the North Atlanta switching station, a distance of 3.6 miles, is constructed a steel tower line of somewhat heavier proportions, the towers on this line being $80 \mathrm{ft}$. in height and weighing approximately 8000 lb., while at certain places along this line an additional 20 -ft. extension was necessary to raise the conductors a sufficient height above the city roadways. This line is known as part of the Atlanta Outer Zone Line, and carries in addition to the two $7 / 16$-in. steel ground wires, and the two 110,000 -volt, $2 / 0$ circuits, two 11,000 -volt lines of $4 / 0$ copper conductors.

The 110,000-volt line from the North Atlanta frame to Lindale is also carried on a double-circuit steel tower line, one circuit of which has not yet been installed. These towers are similar in design to those used on the main Tallulah-Atlanta line, but of lighter construction, and are known as the standard 
$2 / 0$ towers. They measure $16 \mathrm{ft}$. at the base, $4 \mathrm{ft}$. at the top, and are $70 \mathrm{ft}$. high. They were designed to withstand the following loading:

Case 1. A longitudinal pull of $3000 \mathrm{lb}$. at right angles to the end of any one crossarm.

Case 2. A vertical load of $1200 \mathrm{lb}$. at the end of any or all crossarms.

Case 3. A load of $1200 \mathrm{lb}$. pulling in any direction at the top of the tower.

Case 4. A load of $8000 \mathrm{lb}$. pulling at right angles to the line or parallel to the crossarms; that is, $2000 \mathrm{lb}$. at each crossarm. At the same time a pull of $5000 \mathrm{lb}$. parallel to the line or at right angles to the crossarms; that is, $2500 \mathrm{lb}$. at each end of any single crossarm in the same or opposite directions, or at one end of any two crossarms.

The combination of loads used in the design was the same as in the 4/0 towers, and the unit stresses likewise the same.

The power circuit consists of three $2 / 0$ stranded copper conductors, and the ground wire is a $\frac{3}{8}$-in. steel strand, the wires being arranged in a vertical plane the same as on the TallulahAtlanta line, and the spacing likewise the same. The insulators used on this line are of the suspension type, 10 in. in diameter, with five units in series on straight line towers and six units on strain towers. The line is 65.4 miles in length from the North Atlanta station, or 69.2 miles from the Boulevard station.

The 110,000-volt line from Atlanta to Newnan is also carried on the Outer Zone line from the Boulevard station to North Atlanta, and from the latter station to Newnan on a doublecircuit steel tower line of exactly the same design as the Lindale line, just described. Only one 110,000-volt line has been installed on this tower line, but there has been strung on the other side of the towers between the North Atlanta station and Fairburn, Ga., a station some twenty miles distant from Atlanta, a 22,000-volt three-phase 4/0 line, which is being used for supplying the territory around the latter station with low-voltage power until a regular high-tension substation can be built at this latter place, and the second 110,000-volt line strung along the steel towers.

The approximate cost in detail of the Tallulah-Atlanta transmission line is given in the following table: 
Cost of right-of-way, including commissions, surveying, etc................

Legal expense, examination of titles, etc......

Clearing right-of-way $\ldots \ldots \ldots \ldots \ldots \ldots \ldots$

Tower material-steel. . . . . . . . . . . . . 1522.66

Foundations and setting............... 1109.10

Cost of copper conductors . . . . . . . . . . 3563.49

Cost of steel ground wire............... 196.41

Cost of insulation................. 215.44

Cost of stringing conductors............ 486.15

Miscellaneous expenses............ 49.38

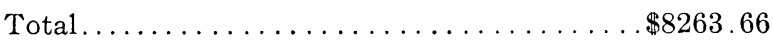

The total unit cost of the Newnan and Lindale lines is given in the following table:

Atlanta-Lindale Line:

Total cost of right-of-way . . . . . . . . . . $\$ 429.87$ per mile

Total cost of tower line ................... 2571.46

Total cost of overhead conductors and insulators, and cost of stringing........ 1282.72

Total..............................\$4284.05

Atlanta-Newnan Line:

Total cost of right-of-way ............. \$ 838.61

Total cost of tower line.................. 2120.51

Total cost of conductors and insulators and cost of stringing................. 1728.78

Total........................ \$4687.90

\section{Telephone Lines}

The power house at Tallulah is connected with the Boulevard station at Atlanta, and the latter station with those at Lindale and Newnan by a telephone line strung along the steel tower line $15 \mathrm{ft}$. below the power conductors. This is a two-wire line of No. 4 copper-clad steel wire, and was originally installed on pin type insulators mounted on steel pins which were in turn bolted to one of the lateral members of the steel towers, and the transposition effected at every tower by means of long and short pins. It was found, however, soon after the power lines were put in operation, that the voltage to ground induced on the telephone line was so great that talking over the line was impossible, and that the insulation could not be maintained intact, so 40,000-volt suspension type insulators were then substituted for the pin type, and the Tallulah-Atlanta line completely reinsulated as. a matter of experiment. After this change was made it was possible to conduct certain tests on the line which showed that the induced voltage went as high as 10,000 volts or perhaps much higher under certain conditions of operation of the power lines, but that this induced voltage 
did not seriously interfere with the talking over the line so long as the insulation was maintained. The other telephone lines were then reinsulated, and as an additional factor of safety, two suspension units of a slightly different design substituted for the one unit. All these lines have been in successful operation since this change. Drainage coils of ordinary $15-\mathrm{kw}$. transformers with the secondary coils open-circuited have been attached to the Tallulah-Atlanta line at both of these stations and also at Gainesville, a station about midway, and similar equipment installed at certain points on the other lines, to keep the induced voltage as low as possible.

Telephone booths are provided along the lines every four miles, and the arrangement is such at these points that the telephone equipment is connected to the line through horn gap switches only while it is being actually used. One-to-one insulating transformers with enclosed fuses are also used as an extra protection to this equipment. Provisions are also made at each of the booths for sectionalizing the telephone lines, and connecting the equipment to either side of the break in testing it out.

Considerable experimental information and advice was obtained when the line as originally constructed could not be made to operate satisfactorily, but nothing of any material value, was accomplished until the insulation problem had been solved in the above described manner. The fact that all of the telephone lines had to be completely reinsulated accounts for the apparently high figures representing the unit cost of these lines as shown in the following table.

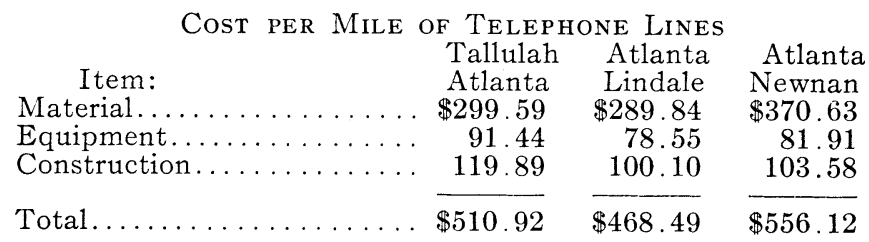

\section{The Boulevard Substation}

The Boulevard substation, Fig. 27, so named because of the street on which it is located, is some two miles north of the main business district of the city of Atlanta, and is the largest station of its particular type which has yet been constructed. It is used as the main distributing station for both high-tension and low-tension power for the Georgia Railway 
\& Power Company's system, and is of the outdoor type, all high-tension structures, transformers and equipment being out of doors, only the low-tension switching equipment being inside the building. It consists essentially of a steel frame approximately $200 \mathrm{ft}$. square, and a two-story brick building containing the main operating room, and all low-tension equipment, in addition to several smaller buildings.

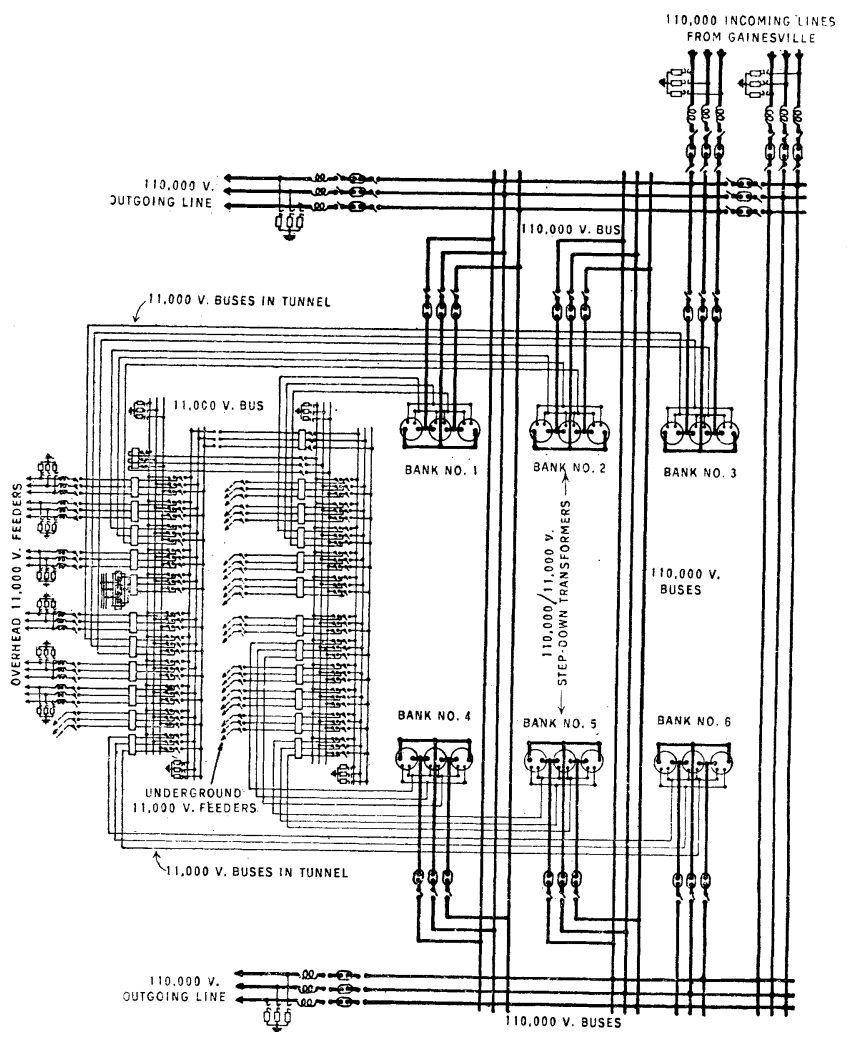

FIG. 28

The steel framework is made up of steel towers similar in design to the regular transmission line towers and connected by latticed steel trusses of standard form. This frame is used for supporting the high-tension buses, disconnecting switches, and all high-tension wiring. The station is designed for an ultimate capacity of $60,000 \mathrm{kw}$., all of the equipment for this rating having already been installed with the exception of 30,000 
$\mathrm{kw}$. in power transformers and their control switches. The transformers now installed consist of three banks of three 3333$\mathrm{kv}-\mathrm{a}$. transformers each, or $30,000 \mathrm{kw}$.

The two incoming lines from Tallulah (see wiring diagram, Fig. 28,) are connected to the high-tension buses through remote control solenoid, operated oil switches of the outdoor type, mounted on concrete foundations immediately beneath the steel structure. Disconnecting switches are installed on both sides of the oil switches, and four-tank three-phase aluminum cell lightning arresters connected to the incoming lines through horn gap switches just before the lines enter the steel structures. Similar switching equipment is also provided between the high-tension buses and the outgoing 110,000-volt lines to Newnan and Lindale, and aluminum cell lightning arresters also connected to these lines just outside the steel framework. Provisions have been made in the foundations for the installation of two additional incoming lines, and one additional outgoing line to each of the stations mentionedm, aking a total of eight high-tension lines to be ultimately connected with this station, part of the steel work for supporting the additional incoming lines having not yet been erected.

The high-tension bus is constructed of $\frac{7}{8}$-in. copper tubing, and is divided into two sections, which may be tied together and operated in parallel by means of an oil switch and disconnecting switches on either side. This bus is supported where it passes under the latticed steel trusses by disk type insulators of six units each, and between such points by standard catenary construction from a $\frac{1}{2}$-in. copper-clad messenger which is itself insulated from the steel framework by strain insulators of six units each.

The transformers are arranged in banks of three each, on both sides of a walkway extending from the entrance to the main building, at one end of the steel framework, along the center line of this structure to the repair shop at the other end of the steel frames, there being provision for three banks in each row, Fig. 29. Running directly along the front of these two rows of transformers, between the transformers and the walkway referred to, are two transfer tracks of standard rail sections, along which the transformers may be carried to the repair shop at the far end of the steel frames by means of a truck provided for this purpose, the truck being of the proper height to permit of rolling the transformers from their foundations 
directly on to the track. At the main building end of these two parallel tracks, are two turntables with a track connecting them, so that a transformer may be moved from one bank to another on the opposite side of the walkway. The track connecting the two turntables is also extended some 75 or 100 feet to the main roadway so that equipment or material can be

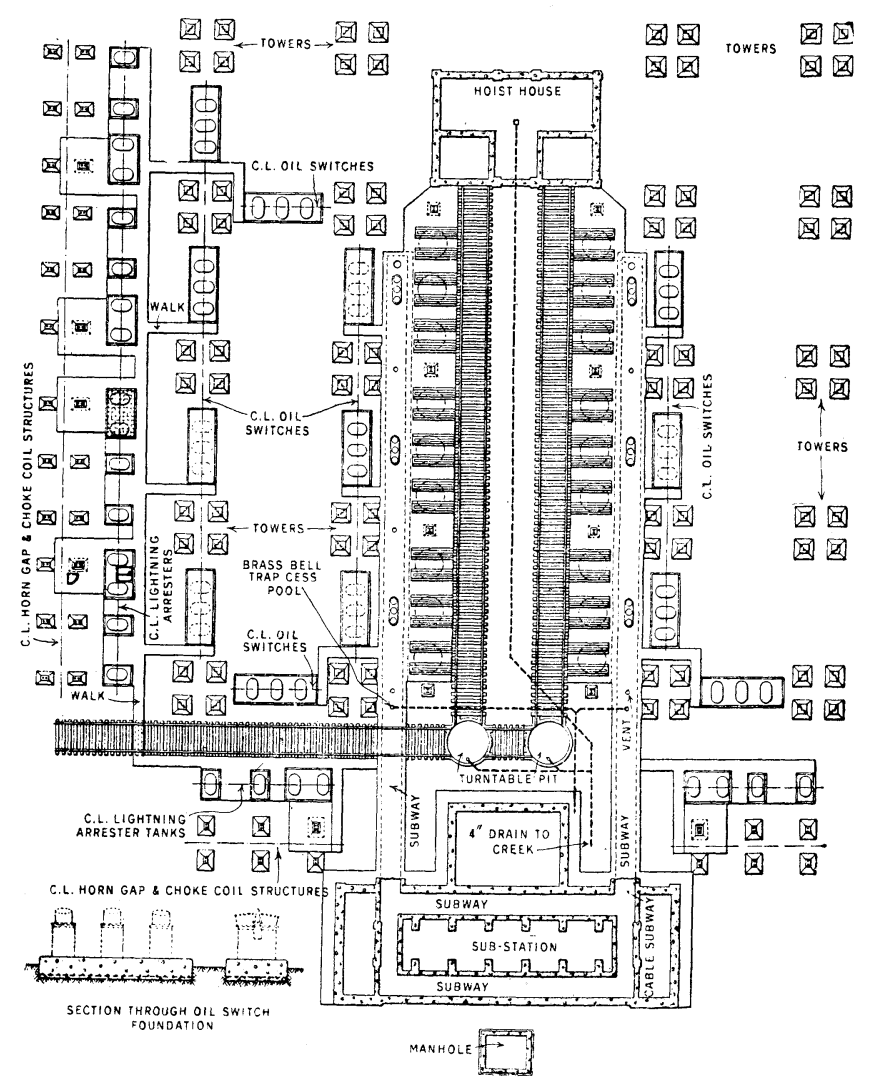

FIG. 29

unloaded from wagons onto the track and then carried directly to the repair shop.

The repair shop is approximately 28 by $42 \mathrm{ft}$., and constructed of high rib steel and cement plaster supported on the steel building frame, with two large steel curtain doors in the front side of sufficient size to permit of rolling the transformers on the truck directly into this shop. This shop is equipped with 


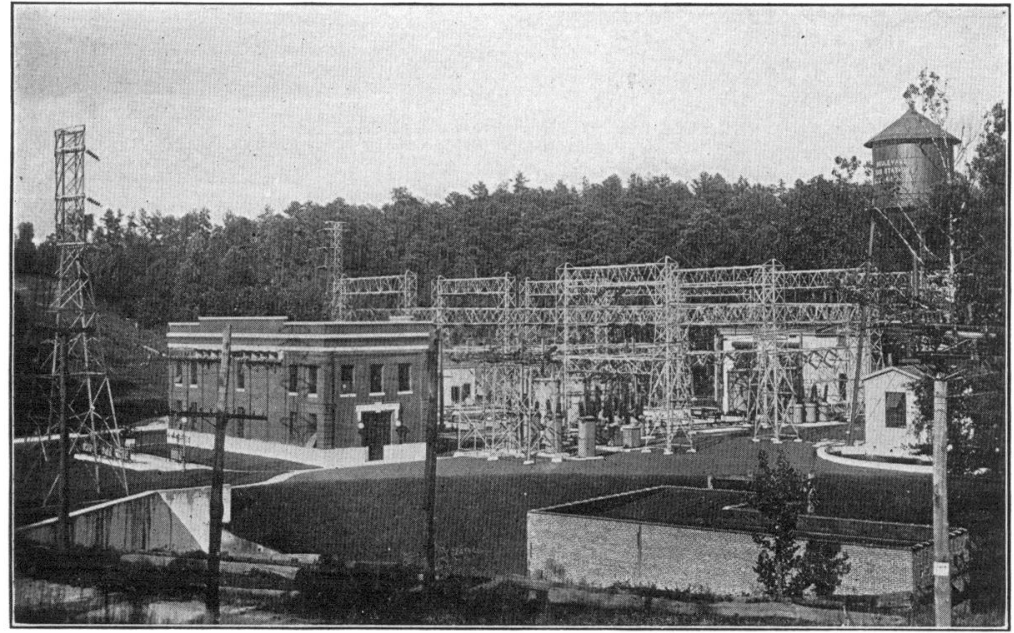

[ADSIT AND HAMMOND]

Fig. 27-Boulevard Substation-Atlanta

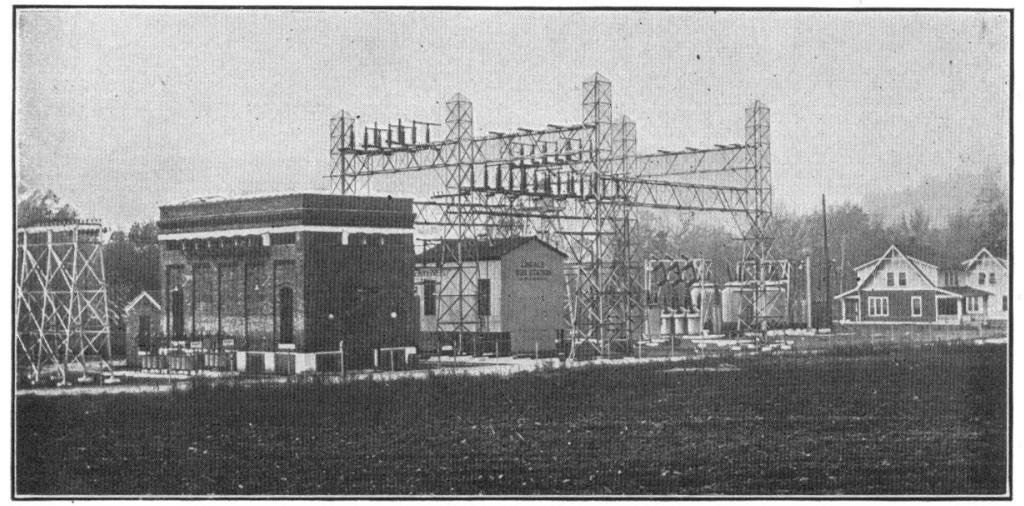

[ADSIT AND HAMMOND]

Fig. 31-Typical Small Substation 
PLATE CXLIX.

A. I. E. E.

VOL. XXXIV, 1915

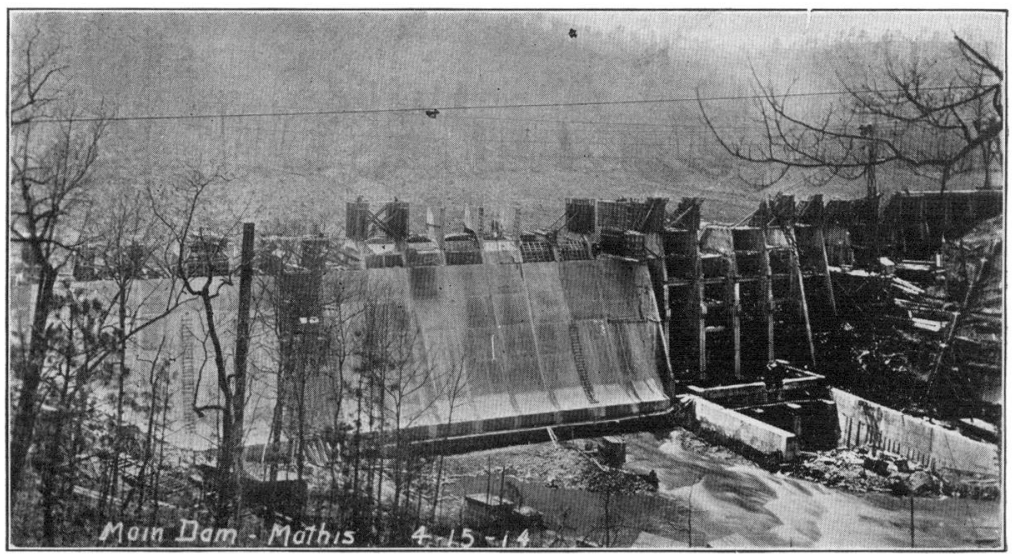

[ADSIT AND HAMMOND]

Mathis Dam During Construction

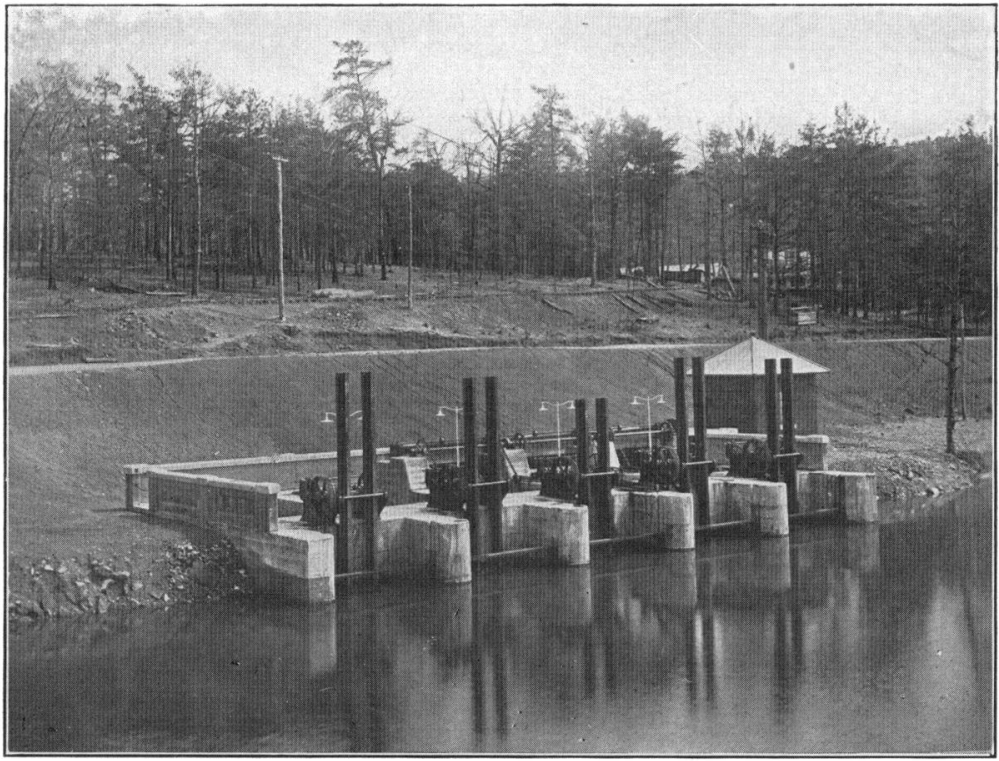

Completed Intake

[ADSIT AND HAMMOND] 
a 10-ton steel crane for handling the transformers, oil filter presses, and storage tanks, as well as a small machine shop, so that all facilities for repairing transformers or other equipment are available, thus keeping the dirt and grease incident to such repairs away from the main substation building.

The oil storage tanks are located in a pit inside the repair house several feet below the surface of the ground, so that the oil in any transformer may be drained into these tanks by gravity through a header which runs along the front of the transformer banks by simply opening the quick-opening valves which are installed between each transformer and this header. This provision was made so that any transformer could in case of fire or other accident be quickly drained of oil. Each transformer is also connected with the oil filter presses through other tanks by a smaller system of piping so that the oil from any transformer may be removed and filtered and then returned to the transformer with the least trouble and expense.

To furnish the water necessary for the cooling system in connection with the transformers, a number of wells were driven on the property at this station to a depth of some four or five hundred feet, and two of these piped up, so that the water may be raised to catch basins at the tops of the wells by compressed air, and then allowed to flow into a large reservoir by gravity, the elevation of the water in the basins being maintained a few feet above that in the reservoir. The main reservoir consists of a concrete basin $61 \mathrm{ft}$. in diameter and $11 \mathrm{ft}$. deep, with side walls some $12 \mathrm{ft}$. thick. There is also erected on a steel tower at an elevation of $75 \mathrm{ft}$. above the water in this main reservoir, a steel storage tank of 50,000 gallons capacity, and the water pumped into this tank from the reservoir below by two vertical submerged centrifugal pumps. The water is then allowed to flow through the cooling system of the transformers by gravity back into the reservoir, except during the hot summer months. when it is considered advisable to admit this water to the waste after passing through the cooling system, that fresh cooler water may be pumped from the wells to the reservoir and thence to the elevated tank. Provisions are also made whereby the water in the tank can be discharged into the reservoir or waste without going through the cooling system when for any reason such a procedure is necessary.

Within the base of the steel tower supporting the storage tank, is built a small pump house similar in construction to 
the repair shop, in which are housed the electric motors for operating the pumps and air compressor, the air compressor and air receiver tanks.

The transformer equipment now installed in this station consists of single-phase, $3333-\mathrm{kv}$-a. shell-type, water-cooled units. The tanks are made of heavy boiler iron $8 \mathrm{ft}$. in diameter with cast iron covers, and measure $13 \mathrm{ft} .6$ in. from the base to the top of the cover. The over-all dimensions from the base to the top of the high-tension leads is $16 \mathrm{ft}$., and the weight of one complete unit including the oil is approximately 25 tons. Each unit is supported on a small truck which rests on steel rails fastened securely to the concrete foundation, and is so placed that it may be rolled from its regular position on to the transfer truck already referred to.

The primary and secondary windings of these transformers are both provided with four $2 \frac{1}{2}$ per cent taps, so that the secondary voltage may be maintained at 11,000 volts with a 10 per cent variation in primary voltage above or below normal of 110,000 volts. Based on a supply of 16 gallons of cooling water per minute, at $15 \mathrm{deg}$. cent., the temperature rise is guaranteed not to exceed $40 \mathrm{deg}$. cent., when operating under full load, or 55 deg. under continuous 25 per cent overload, provided the supply of cooling water is increased to 20 gallons per minute.

The guaranteed efficiencies are as follows:

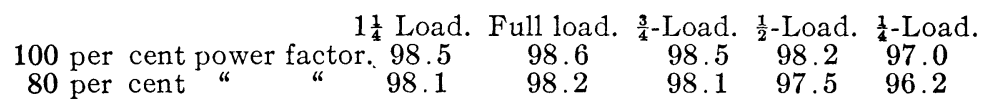

The regulation at 100 per cent power factor is guaranteed not to exceed 0.9 per cent, and at 80 per cent power factor 4.4 per cent.

The transformers were tested by being subjected to a potential of 220,000 volts for one minute between primary and secondary windings and core, and 22,000 volts between secondary and core. A potential of 220,000 volts was also applied across the entire primary windings for five minutes.

The transformers are connected to the high-tension buses through remote control oil switches and disconnecting switches, Fig. 28. The leads from the low-tension windings are carried to the rear of the banks to a delta bus made of copper tubing of large diameter supported on pipe framework, and thence down through large entrance bushings which set in specially 
designed castings in the roof of the tunnels which parallel the two rows of transformers and lead into the basement of the main building. After these leads enter the tunnel they are carried on porcelain insulators along concrete shelves on the side walls to the basement of the low-tension building, thence up through the disconnecting switches in the bus compartments on the first floor of this building to the oil switches located at the tops of these compartments on the second floor of the building. The leads running along the shelves in the tunnel are constructed of $15 / 16$-in. copper tubing to possess sufficient strength to be supported in the above described manner. The other terminals of the low-tension oil switches are connected to the 11,000volt buses, which are located in the first floor of the main building, and similar switches also installed between these buses and the outgoing feeders.

The disconnecting switches on the high-tension frames outside the building, have blades four feet in length, are of very rigid construction, supported by post type insulators of seven units from triangular steel trusses; they overhang at an angle from vertical to make their operation from ground easier for the operator. They are fitted with safety catches to prevent opening of their own accord, and also with specially designed sleet hoods to facilitate their operation during the winter months. All high-tension oil switches are of the remote control, solenoidoperated type, and with the exception of the high-tension bus tie switch, are automatic, being tripped by inverse time relays actuated from current transformers in the switch bushings.

The lighting of the grounds at night is accomplished by incandescent lights fitted with specially designed reflectors so that no light is thrown above the reflectors onto the high-tension wiring, the idea being that defects in the insulation could be more easily detected under such conditions.

The low-tension equipment is all installed in the main substation building. This building is of concrete substructure and red brick superstructure, two stories in height, not including the basement which is connected with the tunnels. It is $81 \mathrm{ft}$. long, approximately $26 \mathrm{ft}$. wide and $27 \mathrm{ft}$. high, inside dimensions. A wing 19 by $26 \mathrm{ft}$. also projects from the center of the building on the side opposite the high-tension structures, the upper floor of which is used as the main control room, and contains the d-c. switchboard, motor-generators, telephone equipment and dispatching office and main control board.

This room 
is fitted with steel sash on the three sides facing the high-tension structures, and because of its location, affords the operator an excellent view of all high-tension equipment and wiring. The lower floor of this wing is used for the main entrance to the building, the battery room, toilets, lavoratories, etc.

The lower floor of the main part of the building is devoted entirely to the switch and bus structures, which are of enclosed constructions, made of pressed brick and alberene stone. On the second floor are installed all low-tension oil switches and station lighting equipment.

There are four sets of 11,000 -volt busbars which are normally tied together so as to form only two sets resembling a double $U$, and the outgoing feeders are connected through an oil switch to either of these buses by means of double disconnecting switches. A set of four-tank, three-phase aluminum cell, 11,000 -volt lightning arresters is installed at each end of this floor, and connected to the two 11,000-volt buses.

All low-tension oil switches between the low-tension bus and the transformers are 15,000-volt, 500-ampere, remote control, motor-operated type, provided with definite time limit relays, while the switches in the outgoing feeders are of the same type but of only 300-ampere capacity. These switches are all operated from the main control board, but are fitted with fourpole switches on the motors which may be opened so that they cannot be operated from the control board, permitting repairs to the switch without fear on the part of the repairman that the switch will be closed.

The low-tension equipment of this station also includes a $30-\mathrm{kw}$. bank of $11,000 / 220-110$-volt transformers and a $75-\mathrm{kw}$. bank of $11,000 / 440$-volt transformers for supplying the energy used in the lighting, motors, pumps, motor-generators, and other station service; also two 10-kw. motor-generators and one 40-ampere-hour storage battery.

The main control board is of the ordinary bench board type with the pull-buttons, mimic buses, lamps, receptacles, etc., located on the bench, and all instruments, relays, etc., on the vertical boards. All oil switches operated from this board are fitted with d-c. trip coils and the power required in their operation drawn from the storage battery, so that any interruption to the high-voltage service will not interfere with the operation of these switches. The motor-generators are used in charging the battery. 
Provisions have been made in this station for six overhead outgoing 11,000-volt lines, and nine underground, all of which have not yet been installed. Each of the outgoing overhead lines is equipped with electrolytic arresters, which are located outside the main building between this building and the deadending structure for these lines, and the connections made to the arresters by an inverted hair pin with a strain insulator between the points.

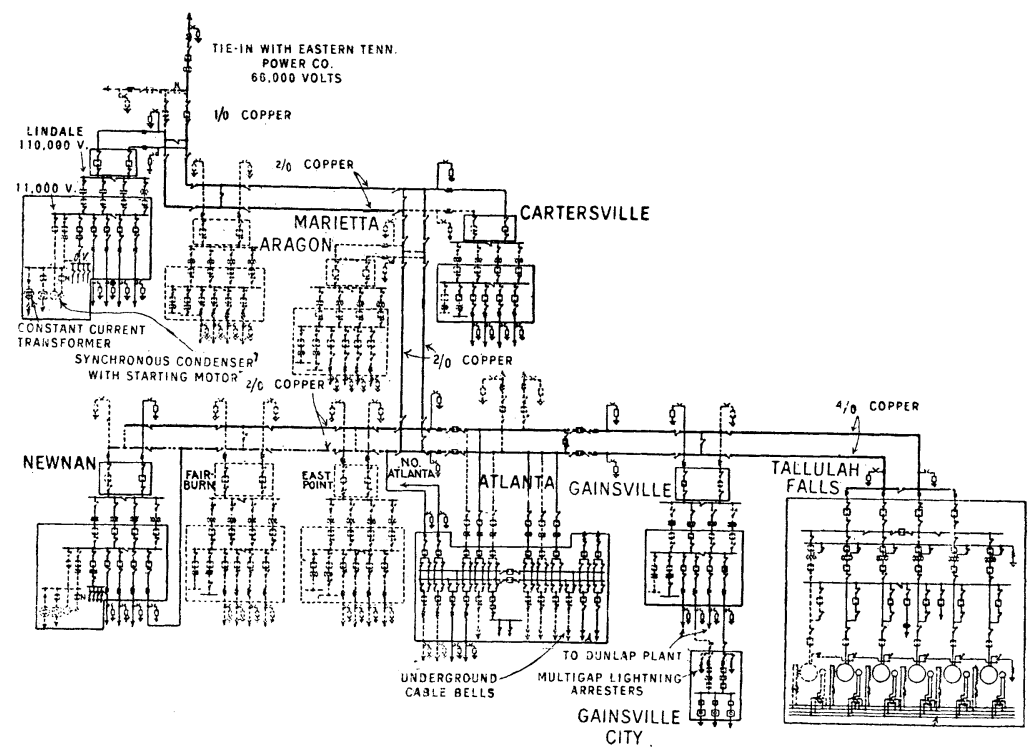

FIG. 30

The total cost of this station is shown in the following unit figures:

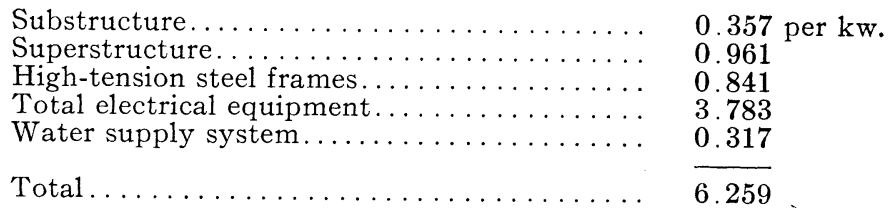

The item total equipment includes both electrical, miscellaneous and substation equipment, for the ultimate capacity of the station $60,000 \mathrm{kw}$. Most of this equipment, with the exception of one-half the ultimate transformer capacity, has already been installed. The above figures were secured by adding to the present known cost of installed equipment an 
additional amount to cover what has not been installed, and therefore represent the cost of the completed substation.

\section{Other Substations}

In addition to the Boulevard station at Atlanta, substations have also been installed at Gainesville, Newnan, Marietta, Cartersville and Lindale, and high-tension frames at East Point, Fairburn and Aragon, Figs. 30 and 31, so that similar stations may be installed at these places when the demand for power at these places justifies the step.

These stations are all almost identical in design, and very similar in general features to the station at Atlanta, so that a brief description of these various stations as a whole is considered sufficient for the purpose of this article.

The high-tension frames cover an area about 70 by $85 \mathrm{ft}$, and the substation buildings are constructed of concrete and brick, one story in height and approximately 40 by $22 \mathrm{ft}$. by $25 \mathrm{ft}$. high, inside dimensions.

The ground wires from the tower lines are connected with the towers in the steel framework, and the 110,000-volt lines connected to the high-tension buses strung under these steel frames through three-pole bolt type disconnecting switches, operated from the ground by means of a long shaft. These switches are not intended to be opened under load, but simply as sectionalizing or disconnecting switches, although it was supposed when they were installed that there would be no difficulty in breaking the charging current of the lines and transformers with them. For both electrical and mechanical reasons, however, they have never been satisfactory, and arrangements have been made whereby all such switches are to be replaced with a more modern type of air-break switch.

The transformers are connected to the high-tension buses through hand-operated automatic type oil switches, which are installed beneath the high-tension structures on concrete foundations and protected to some extent from the weather by a corrugated sheet steel covering of very simple design. The low-tension transformer leads are connected to the delta buses strung between the steel towers, and the connections from these buses to the oil switches inside the station building made as overhead lines, passing through openings in the side walls of the buildings provided for this purpose. The low-tension equipment consists of 15,000-volt hand-operated oil switches installed 
in the transformer secondaries and each of the outgoing feeders, a 15-kw. 11,000/220-110 volt transformer bank for station and lighting service, and the switchboard containing the instruments, meters, etc. Each of the high-tension lines is equipped with aluminum cell lightning arresters, choke coils and horn gap switches, just as at the Atlanta station. The transformers are connected with the oil filter press and storage tank which is buried in the yard outside by a system very similar to that at the Atlanta station, although naturally much less elaborate.

The present and ultimate capacity of the-transformer equipment at each of these stations is given in the following table:

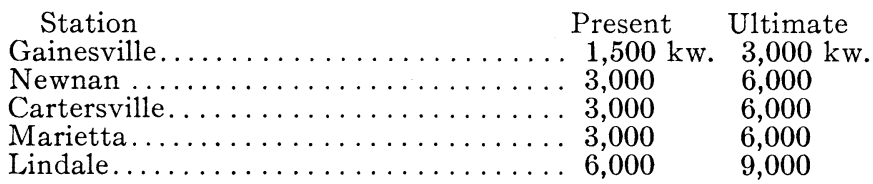

The transformers at all of the stations are self-cooled, singlephase, oil-insulated type, and guaranteed to operate under full load continuously with not more than $40 \mathrm{deg}$. cent. temperature rise or 55 deg. at 25 per cent continuous overload.

The transformers at the Gainesville station are wound for 110,000 volts primary and 11,000 volts secondary, and are equipped with four $2 \frac{1}{2}$ per cent taps on both windings.

The transformers at the other stations are wound for 110,000 or 55,000 volts on the high-tension side, and 22,000 or 11,000 volts on the secondary. These various windings are fitted with the following taps:

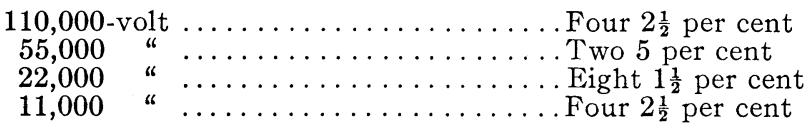

The average unit costs of the typical small substations is given in the following figures:

Substructure................... 0.222 per kw.

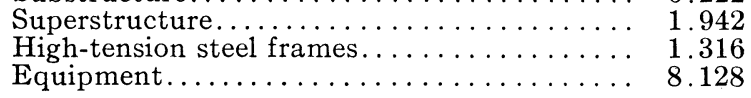

$\$ 11.608$

General

It must be borne in mind that the foregoing costs do not include land or property accounts, with the exception that a typical right-of-way per mile figure is given in the transmission line expenses. These figures only include the actual con- 
struction expenses and the inspection given any particular piece of work. The general engineering expenses are not included, nor are various other general items incident to construction cost as a whole.

The following table gives the percentage relation of various expenses on the development as a whole, which might be applicable to any other development, and therefore does not include the cost of land or property expense:

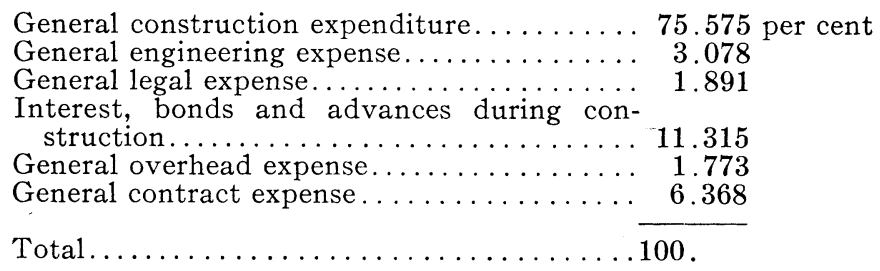

As was the case with the transmission lines and substations, the power plant was operated under the construction department for about one year and the cost of making changes or adjustments, but not the actual operation expense, is included in these figures. The cost, therefore, represents the plant in as perfect an operating condition as contemplated by the design. 
Discussion on "Construction Elements of the Tallulah Falls Development" (Adsit and Hammond), Philadelphia, Pa., October 11, 1915.

A. J. Porskievies: I ask Mr. Adsit to tell us what type of rotor the generator has, and also whether there is any reactance protection from short circuit, and whether the generators are operated with the grounded neutral; and finally, whether the efficiency of $95 \frac{1}{2}$ per cent on the generator includes friction.

A. S. Loizeaux: I would like to have the author explain the operation of the operating flashboard as detailed in Fig. 8.

A. J. Porskievies: It is a very extended transmission system in a country noted for thunderstorms and I would be glad to have the author tell us about lightning troubles.

C. G. Adsit: I rather think this is a stronger rotor than is usually used with vertical steam turbines. The rotor is built of solid steel disks with the pole pieces dovetailed thereto. The pole pieces in addition to this support have steel end rings which are bolted to the outer end to sustain the winding. The rotor is also provided with fans on each end to promote a circulation of about $35,000 \mathrm{cu}$. ft. of air per min. It is my understanding that the efficiency of 96 per cent includes all friction and the blowing of air for the generator ventilation.

C. O. Lens: The flashboards used on the crest of the intake dam and also on the crest of the storage dam, are a type which has been used extensively in Switzerland. It consists of a board hinged at the bottom, which is fastened to the crest of the dam; at the upper end of this flashboard cables are attached. These cables in turn are connected to grooved winding drums, these winding drums being a counterweight to the pressure which is back of the board. The board, if mathematically worked out, it will be seen, requires about equal inertia in any position to move one way or the other, depending on the true balance condition that may exist and so forth. So it is a movement depending on which predominates, whether it is the water pressure or the dead weight of the rolling weight. This rolling weight runs up a toothed rack, and its form is such that it requires practically the same inertia to move in whatever position it is in. These boards have been in operation in countries where they have been subjected to ice, although there may be some question whether they would be satisfactory in releasing heavy ice over the top or not. In this particular case, we considered that there would be no real objection for there would be no ice present. So there is really nothing but a moving, rolling weight against the hydrostatic pressure back of the board.

Mr. Biglow: Is there any trouble with trash coming down?

C. O. Lens: No, they have found very little trash accumulates and there is no trouble with it on the racks. Even the amount that flows on the surface is not of very great moment. 
A reservoir dam is back of the intake dam, and it accumulates there, unless the floods take it over. hachee.

Mr. Biglow: I have seen a good deal of it on the Chocto-

C. O. Lens: No, there would not be much, because the back ridge is pretty heavily wooded and timbered and the reservoir back of the storage dam, as well as the reservoir of the intake dam, was particularly well cleared. It was not only detimbered, but practically everything was cleared off so there is very little trouble from foreign matter carried over the dam.

Geo. A. Hoadley: I have been interested in the comparison between two of the expenses mentioned in the last table. This appears to be a work in which the engineering operation is the larger element, but I have been considerably surprised in noticing that the general engineering expense is but $\$ 3.07$, while the general legal expense is $\$ 1.89$, considerably more than one-half of the general engineering expense. Now is there any particular explanation of that? That is, does it include anything more than the searching of titles and such legal work?

C. G. Adsit: This item of legal expense does not include any abnormal charges. It is my belief and experience that 1.7 per cent for legal expense is low rather than high. I think on ork as large as this and especially water power work involving various water rights and transmission lines involving the condemning of property, that you usually find as many lawyers as you do engineers in connection with the development.

There was one question regarding reactance. We have no special reactance in the generating station of Tallulah Falls beyond that in the generators themselves. That is, no external reactance to limit the current on short circuit. The high-tension side of the transformer installation is connected in star with the neutral grounded. In case the transmission line conductors are grounded there is a resistance provided between the ground connection and the transformer neutral which is intended to limit short-circuit current. We have had only one instance, so far as we know, where the transmission lines have fallen and that was on a connected system and not on our own. The only evidence at that time that anything unusual had taken place was the indication of fluctuating load on the generators and the heating up of this ground resistance. Otherwise we would not have known that a short circuit had occurred. We did not see the necessity of external reactance in this installation unless the short circuit occurred on the low-tension conductors. We are protected against this occurrence as nearly as possible with the proper construction without the use of reactance. There has been but one short circuit on the low-tension conductors and that between conductor and ground, which was caused by rats standing on the pipe supports and reaching the conductors. What the magnitude of this short circuit was we do not know, except that it seriously burned the switch cell structure. 
Harold Pender: What about lightning?

C. G. Adsit: Yes, something was said about lightning troubles. We have not had any serious lightning troubles of any nature. While we have not been entirely free of lightning disturbances the shut-down sdue to this cause have been very few and it has been uncertain as to whether these shut-downs were due to lightning or other disturbances.

R. B. Owens: Are your arresters at the receiving end only, or where are they?

C. G. Adsit: At both ends and in the center of the transmission lines.

R. B. Owens: How did you determine that was the best place for them?

C. G. Adsit: It was the convenient place rather than the best place.

R. B. Owens: You charged them every day?

C. G. Adsit: Every night when the load is light we charge the arresters at each location.

R. B. Owens: What has been your experience with the outdoor type of high-tension switch?

C. G. Adsit: Well, we are changing them all now. I might say to that question that we have made a great many experiments on outdoor switches in connection with this transmission line. We find that the various types of outdoor switches had no trouble in opening the energy current, but they would not open the charging current of the line.

Lars Jorgensen: The figures given seem to be reasonable and about what could be expected for the character of work done. There is possibly one exception, that of the diverting dam. For this the authors state that the cost was about $\$ 3.70$ per cubic yard in place. For the mix given, the cement will cost $\$ 1.40$, taking into account that only two-thirds of a yard of actual concrete is needed per unit volume of structure, the remaining one-third being rock thrown in after pouring. This leaves $\$ 2.30$ per yard for rolling sand, mixing concrete, construction plant, the rock portion, etc. Some of the rock excavated from the foundation and for which the contractor was paid $\$ 1.50$ per yard can possibly be used for plumstones, but much more would undoubtedly have to be quarried for the purpose, therefore the price given seems exceptionally low and the work must have been done in a very economical manner. Thirty-four per cent of "plums" in a dam is a large percentage, and it has undoubtedly required some hand placing to get this large percentage in. The fact that the dam has cracked but little is probably due to the presence of this large percentage of plumstones, and to the fairly slow progress made (1000 yards per week), and because the dam was mostly built during the winter. The slight curvature given the dam could not be expected to keep down any tendency to develop cracks which might exist.

The paper does not give any information as to the saving 
effected by substituting the welded penstock pipes for riveted pipes towards the lower end. It would be very interesting to know something about this, both as to the money saving effected and the head gained. This head has undoubtedly been measured by this time.

The writer had an opportunity to watch a welded 30-inch diameter pipe go in this summer on a hydroelectric installation utilizing about $1280 \mathrm{ft}$. head. This pipe was made in the United States in a manner similar to that in use in Germany, and was in every respect an excellent piece of work. From tests made to determine the strength of the weld it was learned that the joint efficiency was between 96 per cent and slightly above 100 per cent. That it could be above 100 per cent is probably due to the fact that the material is worked more at the lap when being welded. The maximum plate thickness in the welded portion of the pipe was $\frac{1}{4}$ inch. Below this thickness riveted pipe was used, but this was a very small portion of the total. The saving effected in comparison with a riveted pipe was quite material. 